\title{
Neoblast-enriched zinc finger protein FIR1 triggers local proliferation during planarian regeneration
}

\author{
Xiao-Shuai $\operatorname{Han}^{1}$ (]), Chen Wang ${ }^{1}$, Fang-hao Guo ${ }^{1}$, Shuang Huang ${ }^{2}$, Yong-Wen Qin ${ }^{2}$, \\ Xian-Xian Zhao ${ }^{2}$, Qing Jing ${ }^{1,2 \bowtie}$ (D) \\ ${ }^{1}$ Key Laboratory of Stem Cell Biology, Institute of Health Sciences, Shanghai Jiao Tong University School of Medicine \& \\ Shanghai Institutes for Biological Sciences, Chinese Academy of Sciences, Shanghai 200025, China \\ 2 Department of Cardiology, Changhai Hospital, Shanghai 200433, China \\ $\bowtie$ Correspondence: qjing@sibs.ac.cn (Q. Jing) \\ Received July 6, 2017 Accepted January 9, 2018
}

\begin{abstract}
Regeneration, relying mainly on resident adult stem cells, is widespread. However, the mechanism by which stem cells initiate proliferation during this process in vivo is unclear. Using planarian as a model, we screened 46 transcripts showing potential function in the regulation of local stem cell proliferation following $48 \mathrm{~h}$ regeneration. By analyzing the regeneration defects and the mitotic activity of animals under administration of RNA interference (RNAi), we identified factor for initiating regeneration 1 (Fir1) required for local proliferation. Our findings reveal that Fir1, enriched in neoblasts, promotes planarian regeneration in any tissue-missing context. Further, we demonstrate that DIS3 like $3^{\prime}-5^{\prime}$ exoribonuclease 2 (Dis3/2) is required for Fir1 phenotype. Besides, RNAi knockdown of Fir1 causes a decrease of neoblast wound response genes following amputation. These findings suggest that Fir1 recognizes regenerative signals and promotes $D I S 3 L 2$ proteins to trigger neoblast proliferation following amputation and provide a mechanism critical for stem cell response to injury.
\end{abstract}

KEYWORDS local proliferation, adult stem cells, Dis3/2, wound recognition, planarians, Schmidtea mediterranea

Electronic supplementary material The online version of this article (https://doi.org/10.1007/s13238-018-0512-0) contains supplementary material, which is available to authorized users.

\section{INTRODUCTION}

Regeneration is a common phenomenon throughout the animal kingdom. For example, in mammals, hair follicle and epidermis can regenerate following injury (Fuchs and Segre, 2000; Seifert et al., 2012), and some invertebrates such as Hydra are capable of whole-animal regeneration from tissue pieces (Govindasamy et al., 2014; Sanchez Alvarado, 2000). There are two general regeneration groups: epimorphosis, which comprises all cases of regeneration that involve proliferation to form new tissue, and morphallaxis, in which regeneration can occur in the absence of cell proliferation (Morgan, 1901). The source of proliferative cells varies among the organisms exhibiting epimorphic regeneration. Adult stem cells (ASCs), residing in adult tissues, are undifferentiated cells and divide to replenish senescent cells and regenerate wounded tissues (Beachy et al., 2004; Clarke et al., 2000). The proliferation of ASCs is essential to initiate regeneration. It is reported that many signaling pathways are involved in the regulation of adult stem cell proliferation. For example, the transforming growth factor- $\beta$ signaling is implicated in the control of muscle stem cell proliferation during adult skeletal muscle regeneration (Carlson et al., 2008), while canonical Wnt signaling promotes the proliferation of peripheral olfactory stem cells during the peripheral olfactory regeneration (Wang et al., 2011). However, these signals come from extrinsic molecules, the intrinsic regulators that govern adult stem cell proliferation in vivo remain largely elusive.

Planarians are a classical model for studying regeneration, as they can regenerate their whole bodies after amputation even from little pieces (Morgan, 1898; Reddien and 
Sanchez Alvarado, 2004). This amazing regenerative capacity relies on a population of adult stem cells named neoblasts (Reddien and Sanchez Alvarado, 2004), which are constantly dividing to replenish all cell types in intact animals (Newmark and Sanchez Alvarado, 2000; Pellettieri and Sanchez Alvarado, 2007). Neoblasts proliferate following wounding and are the source of new cells for regeneration (Best et al., 1968). Upon amputation, neoblasts display two waves of proliferating response: one commencing 6-8 h following wounding, whereby proliferation increases throughout the body, followed by another occurred $40 \mathrm{~h}$ later, in which proliferation is restricted to the wounds (Wenemoser and Reddien, 2010). The first wave is triggered following all injury types, while the second wave is specific to 'missingtissue' response (Wenemoser and Reddien, 2010; Wurtzel et al., 2015). Many genes were mainly expressed in neoblasts and could regulate neoblast proliferation during regeneration. For example, Smed-hp1-1 triggers neoblast proliferation by inducing the expression of Mcm5 (Zeng et al., 2013). However, Smed-hp1-1 is required for all neoblasts proliferation, not specifically for proliferation near the wounds. The intrinsic regulatory mechanisms of neoblasts that promote local proliferation responding to wound are poorly understood. Following amputation, a class of woundinduced genes was activated directly within neoblasts (e.g., runt-1 and cdc25-1) (Wenemoser et al., 2012). Moreover, a recent study has revealed that all kinds of injury activate a common wound-response transcriptional progress, and neoblasts express most wound-induced genes (Wurtzel et al., 2015). These findings suggest that neoblasts play critical roles in response to early injury. Nevertheless, the neoblast intrinsic genes controlling neoblast wound response are needed to be identified.

In the present study, we identified that Fir1 was required for local proliferation response for regeneration. Fir1 is mainly expressed in neoblasts and promotes regeneration following amputation. Further, we found that Dis3/2 is required for Fir1 phenotype. Moreover, the expression of neoblast wound response genes is reduced in Fir1(RNAi) animals following amputation. These results suggest that Fir1 senses regenerative signals and promotes $D I S 3 L 2$ proteins to trigger neoblast proliferation following amputation and provide a mechanism critical for neoblast response to injury.

\section{RESULTS}

Identification of Fir1 required for local proliferation by screening

We aimed to identify neoblast intrinsic regulators required for local proliferation and explore the mechanisms underlying their function (Fig. 1A). In mammals, the proliferation of adult stem cells is essential for regeneration. Thus, considering the findings reported in the extant literature, we hypothesized that if there exist neoblast intrinsic regulators required for local neoblast proliferation, these genes could strongly
Figure 1. Fir1 is required for local neoblast mitosis. (A) The scientific question needed to be addressed. The mitosis adjacent to the wounds is specifically induced by tissue-missing injury (Wenemoser and Reddien, 2010), while neoblast intrinsic regulators involved in this process are still unknown. (B) Representative confocal projections through tail pieces fixed $48 \mathrm{~h}$ post-amputation following RNAi administration, stained with $\mathrm{H} 3 \mathrm{P}$ antibody. The wound surfaces of tail pieces are up. Dotted lines (white): tail piece boundary. Dotted lines (blue) separate the tail pieces into two parts for quantification in (C). Unless otherwise noted, animals were fed $2 \times$ dsRNA and amputated as indicated in the cartoon (dotted red lines). Scale bars, $100 \mu \mathrm{m}$. (C) Mitotic density in part 1 and part 2 as separated in (B). Only one gene, Fir1, satisfies our screen criterions. In Fir1(RNAi) tail pieces mitotic density in part 1 reduced significantly, while in part 2 it was not deceased. Error bars represent SEM; * equals $P<0.05$; ${ }^{* *}$ equals $P<0.0001$; significance determined with Student's $t$ test. (D) Fir1 RNAi did not affect neoblast number (percentage of $\mathrm{X} 1$ cells) as assayed by flow cytometry. Error bars represent SEM; * equals $P<0.05$; ${ }^{* *}$ equals $P<0.001$; significance determined with Student's $t$ test. (E) Representative confocal projections through tail pieces fixed $0 \mathrm{~h}$ and $7 \mathrm{~h}$ post-amputation following RNAi knockdown of Fir1, stained with H3P antibody. Dotted lines: tail piece boundary. (F) Quantification of H3P staining in (E). These results indicate that Fir1(RNAi) do not affect the general response of neoblasts to amputation. Error bars represent SEM; * equals $P<0.05$; significance determined with Student's $t$ test.

promote planarian regeneration. First, we searched published papers for reports on neoblast regulators and phenotypic transcription factors screened by RNA interference (RNAi) and aimed to identify them in our lab. Considering the strength of regenerative phenotype upon RNAi and the expression pattern, we finally chose 46 genes, which were reported to strongly promote planarian regeneration and be enriched in neoblasts, as candidates for screening (Almuedo-Castillo et al., 2014; Blassberg et al., 2013; Bonuccelli et al., 2010; Böser et al., 2013; Chen et al., 2013; Gonzalez-Estevez et al., 2012; Guo et al., 2006; Hollenbach et al., 2011; Labbe et al., 2012; Li et al., 2011; Onal et al., 2012; Oviedo and Levin, 2007; Palakodeti et al., 2008; Rossi et al., 2007; Rouhana et al., 2010; Salvetti et al., 2005; Sanchez Alvarado, 2000; Scimone et al., 2010; Solana et al., 2012; Wagner et al., 2012; Wenemoser et al., 2012; Zayas et al., 2005; Zeng et al., 2013; Zhu et al., 2015; Zhu and Pearson, 2013) (Table S1 and Fig. S1A). In the next phase of our study, we examined regeneration phenotypes of these genes after two rounds of dsRNA feeding and found that trunk pieces showed severe regeneration defects following each of 23 genes RNAi (Fig. S1B). We randomly chose 6 
A
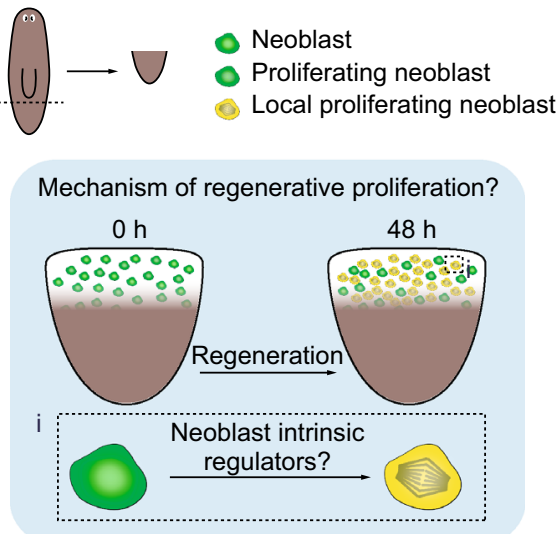

B
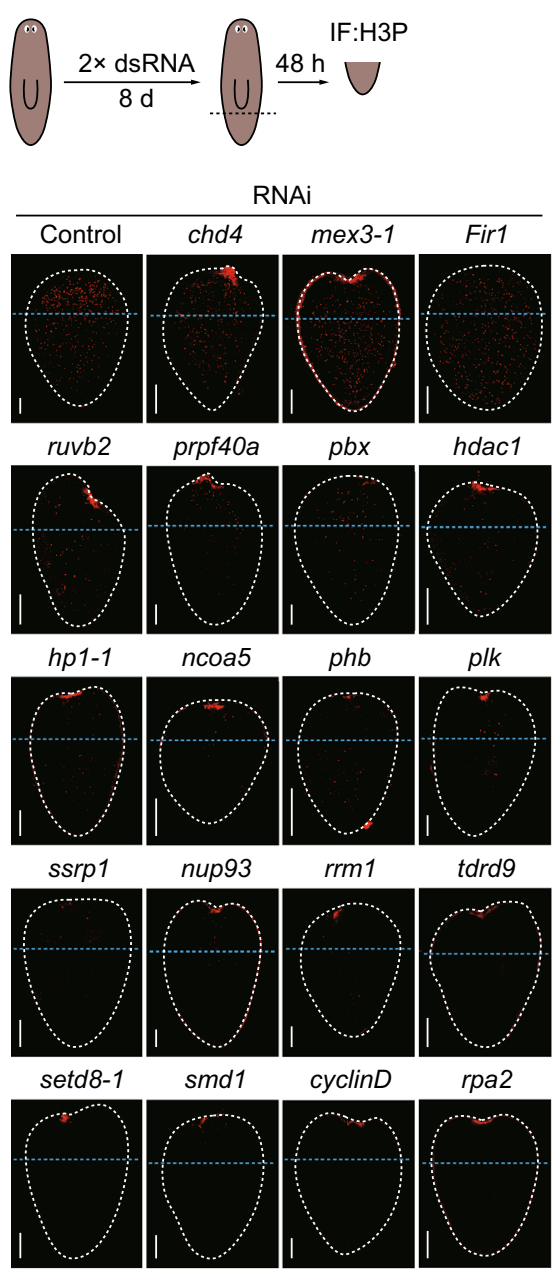

ctr9

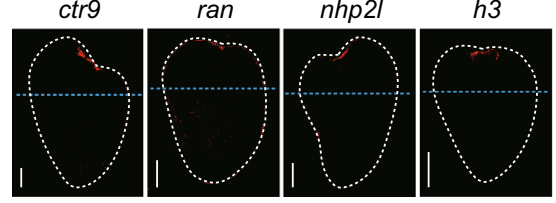

C
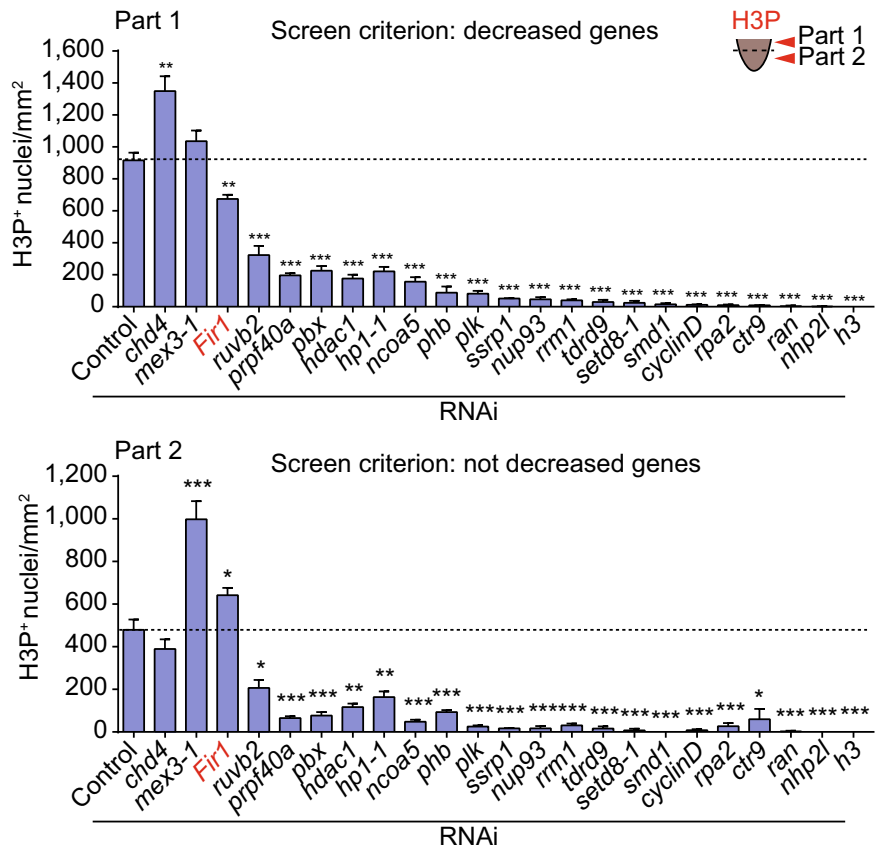

D

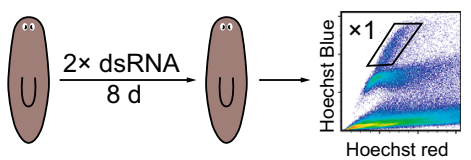

Screen criterion: invariable genes

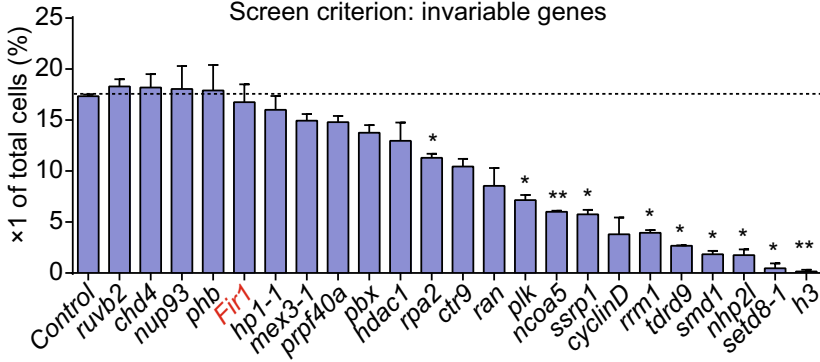

E
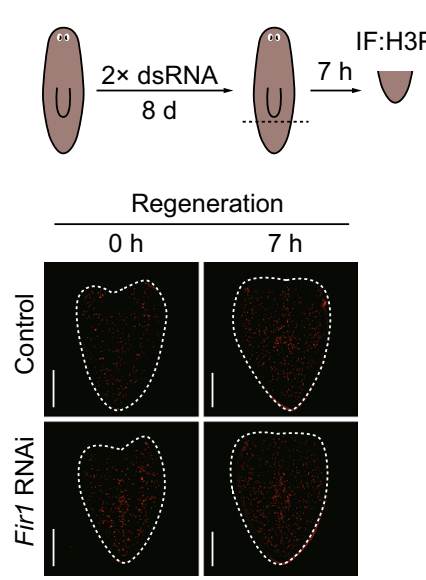
genes to validate their RNAi efficiency, and we found that the gene expression reduced to about 30\% following each of 6 genes RNAi, suggesting that our RNAi is efficient and has no off-target (Fig. S1C). In addition, we stained the tail pieces $48 \mathrm{~h}$ post-amputation using an antibody recognizing phosphorylated histone $\mathrm{H} 3$ at serine 10 (H3P) upon RNAi knockdown of each of the 46 candidates. Our observations revealed that mitotic activity decreased significantly at this time point after inhibition of most genes, indicating that many neoblast regulators could control neoblast proliferation generally (Fig. 1B). To confirm this observation, we quantified mitoses in each of two defined regions: adjacent to the wound sites (part 1) and the remaining tail piece (part 2). Indeed, we found that the mitotic density decreased dramatically following inhibition of each of 23 genes in both regions, such as ruvb2, prpf40a, pbx, hdac1, etc. (Fig. 1C). We also found that the mitotic events after RNAi knockdown of two genes (chd4 and mex3-1) changed differently (Fig. 1C). chd4(RNAi) caused mitoses to increase dramatically at part 1 with no change at part 2 , while mex3-1(RNAi) caused mitoses to increase dramatically at part 2 with no change at part 1 , consistent with their main function in neoblast differentiation (Fig. 1C). Interestingly, we identified a new gene, Fir1, knockdown of which caused mitoses to diminish significantly at the wound sites, without affecting remaining tail pieces (Fig. 1C). To explore the delicate change of mitoses in Fir1(RNAi) tail pieces, we quantified the mitotic density from the wound sites and found that Fir1 (RNAi) tail pieces displayed reduced mitotic neoblasts in the region of $150 \mu \mathrm{m}$ away from the wounds (Figs. 1B and S1D). Furthermore, we examined neoblasts in the vicinity of wound sites in Fir1(RNAi) tail pieces $48 \mathrm{~h}$ post-amputation, and as was expected, the HP1-1 ${ }^{+}$and the SMEDWI- $1^{+}$neoblast population were reduced in Fir1(RNAi) animals (Fig. S1E). These results demonstrate that Fir1 was required for local proliferation near the wounds.

If these 23 genes mentioned above mainly play roles in maintaining the local proliferation $48 \mathrm{~h}$ post-amputation, they should not affect the neoblast population in homeostasis (Gavino et al., 2013; Wenemoser and Reddien, 2010). Therefore, we examined ' $X 1$ ' population (referred to as neoblasts in FACS) after inhibiting each of the representative 23 genes respectively, and found that the percentage of ' $\mathrm{X} 1$ ' population was comparative to the control after inhibiting 13 genes, indicating that at this time point these genes might have no effects on neoblast maintenance in homeostasis (Fig. 1D). Strikingly, Fir1 was included in these 13 genes, indicating that Fir1(RNAi) does not affect neoblast maintenance before amputation. Furthermore, we investigated neoblast population and mitotic activity in intact Fir1(RNAi) animals at different time points, and we found that the neoblast population and the mitotic density appeared indistinguishable compared to control after Fir1 RNAi (Fig. S1F and $\mathrm{S} 1 \mathrm{G})$. We also found that Fir1(RNAi) animals displayed homeostasis defects following long-term RNAi (Fig. S1H). The number of neoblast early $\left(\operatorname{prog}-1^{+}\right)$and late (agat $-1^{+}$) progenies decreased following Fir1 RNAi (Fig. S1I). These results suggest that Fir1 is required for neoblast differentiation in homeostasis, which was not mainly discussed in this paper.

To exclude the possibility that Fir1(RNAi) affects neoblast generic response 6-8 $\mathrm{h}$ after injury, we examined the mitotic activity $0 \mathrm{~h}$ and $7 \mathrm{~h}$ post-amputation in Fir1(RNAi) animals (Fig. 1E). After quantification of the mitotic density, Fir1 (RNAi) animals displayed neoblast generic response (Fig. 1F). Taken together, these results suggest that Fir1 specifically controls local proliferation in early regeneration.

\section{Fir1 is required for missing-tissue regeneration}

In our screening, Fir1(RNAi) animals could not regenerate blastemas after amputation (Figs. 2A, arrowheads, S1B and $S 2 A$ ). The regeneration defects were confirmed by staining Fir1(RNAi) trunk pieces with gastrointestinal system marker (Porcupine) and nervous system marker (PC2) 8 days post-amputation (Fig. 2B). We designed a different double-strand RNA (dsRNA) and using this dsRNA we obtained the same regeneration defects as with the dsRNA described above, indicating that Fir1(RNAi) phenotype is specific (Fig. S2B).

To specify the regeneration phenotype after inhibition of Fir1, we inflicted some other injury types to planarians, including a large incision, excision of lateral tissue wedge, removal of head tips, and removal of eyes. We observed that Fir1(RNAi) animals could repair the large incision, while Fir1 (RNAi) animals were not able to regrow in other injury conditions, indicating that Fir1 was required for missing-tissue regeneration (Fig. 2C).

\section{Fir1 mRNA is predominantly expressed in neoblasts}

To detect Fir1 expression pattern, we produced Fir1 probe and Fir1 sense probe corresponding to the same region. The Fir1 probe could detect Fir1 mRNA robustly, while Fir1 sense probe detected nothing by colorimetric whole-mount in situ hybridization (WISH), suggesting that our Fir1 probe is specific to Fir1 mRNA (Fig. S3A). By applying this probe, we found that Fir1, like many reported neoblast regulators, was mainly expressed in the planarian parenchyma (Fig. S3A). A lethal dose of gamma-irradiation (6,000 rad) depletes neoblasts of planarians, eliminating the ability to regenerate and to replace aged cells during homeostasis (Bardeen and Baetjer, 1904; Dubois, 1949; Scimone et al., 2010). Interestingly, $48 \mathrm{~h}$ after lethal irradiation, almost all Fir1 mRNA was undetectable as smedwi-1 mRNA, indicating that Fir1 is expressed in neoblasts (Fig. 3A). Furthermore, we found that 93.3\% of Fir $^{+}$cells co-expressed smedwi-1 mRNA, while little Fir1 mRNA was expressed in prog $-1^{+}$or agat $-1^{+}$cells by double fluorescent in situ hybridization (dFISH) (Figs. 3B, S3B and S3C). Fir1 mRNA was also expressed in the nervous system by detecting Fir1 and $\mathrm{PC}-2 \mathrm{FISH}$ probes 
A
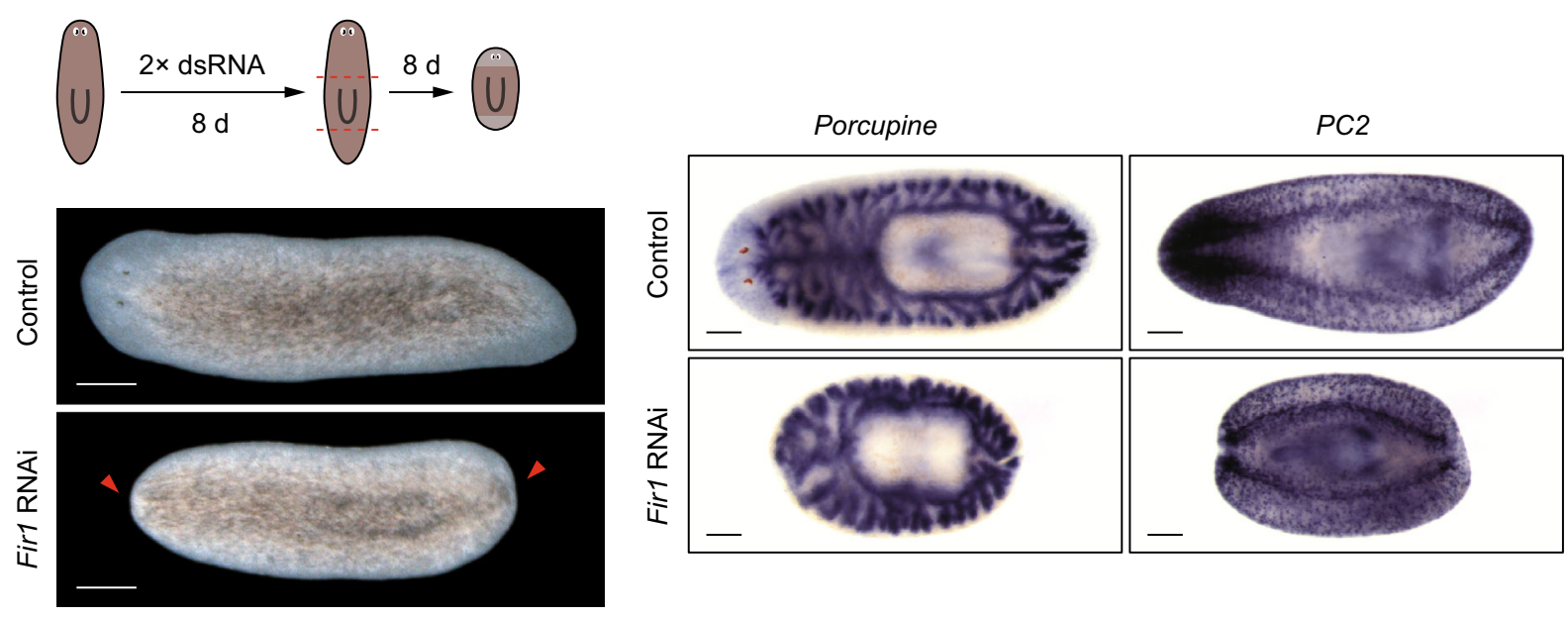

C
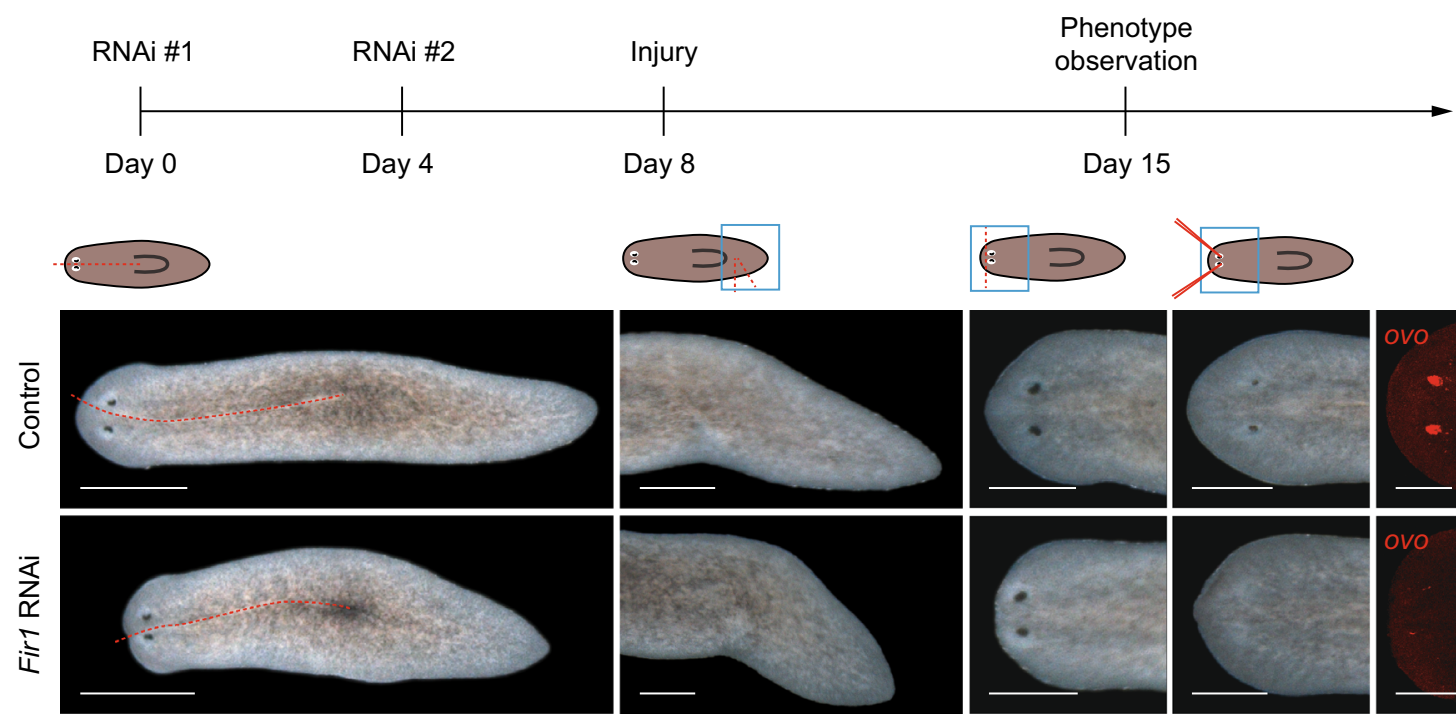
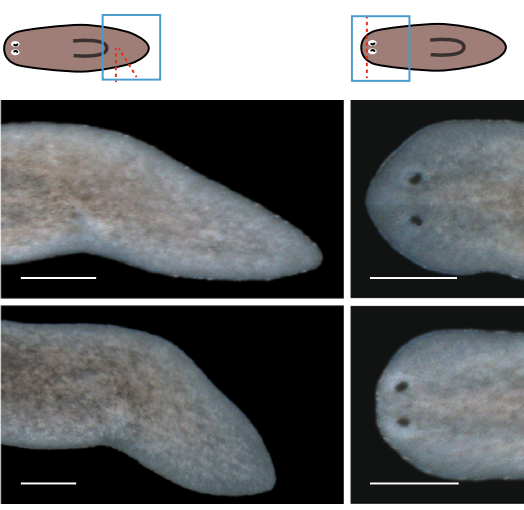

B 


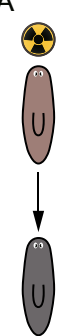

G
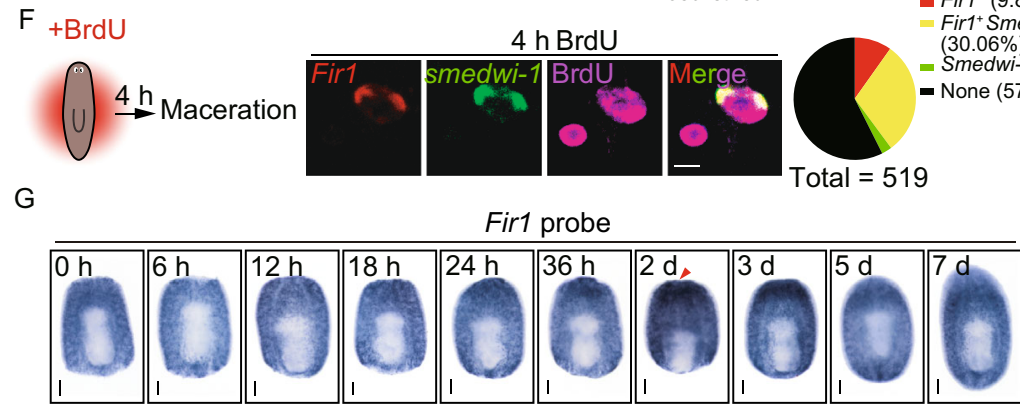

+ BrdU

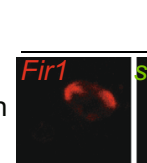

$4 \mathrm{~h} \mathrm{BrdU}$

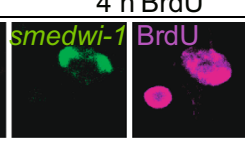

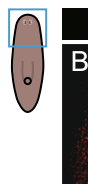
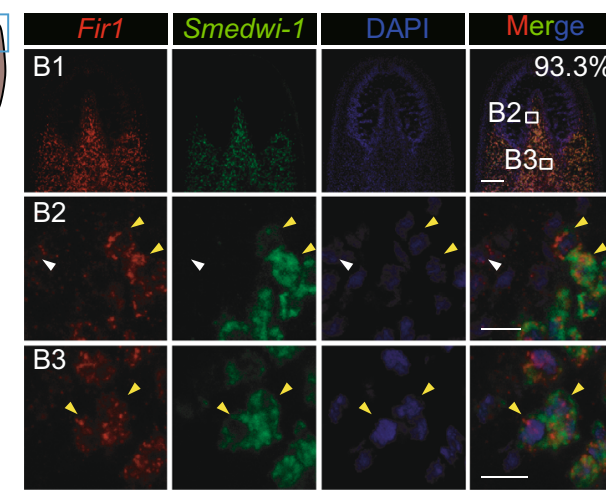

C
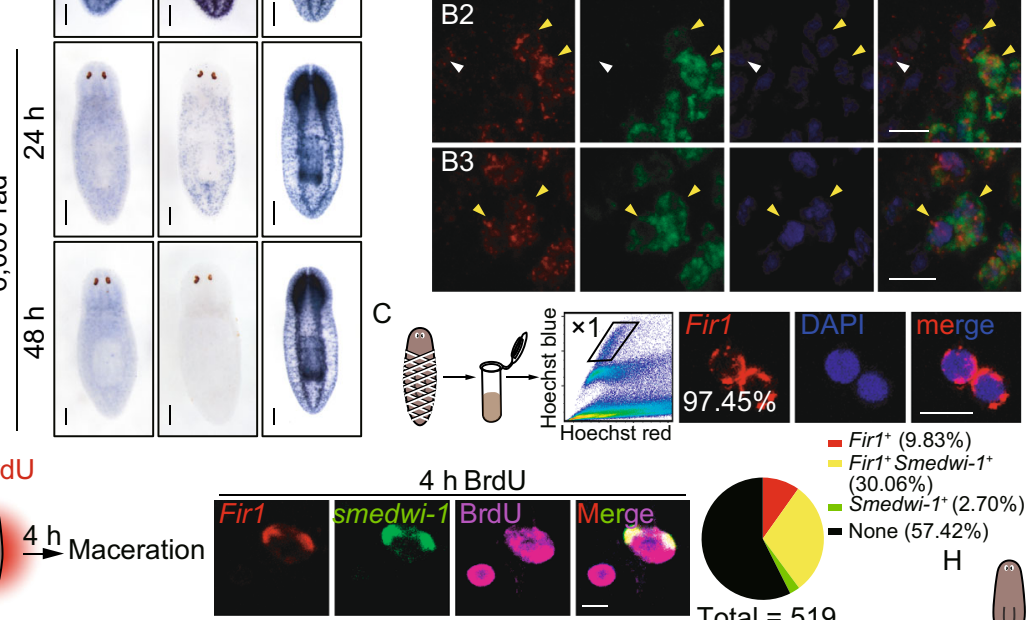

Fir1+ Smedwi(30.06\%)

(2.70\%) None $(57.42 \%)$
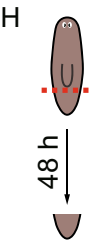

IF:H3P
D

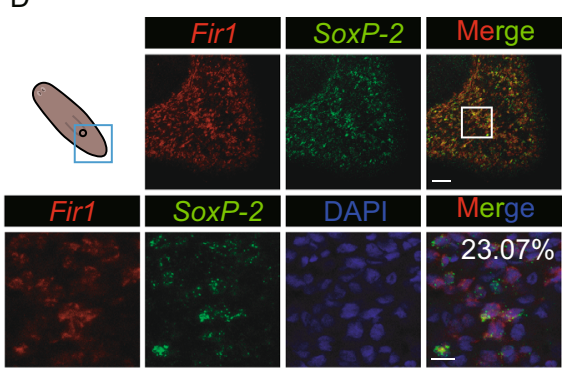

E
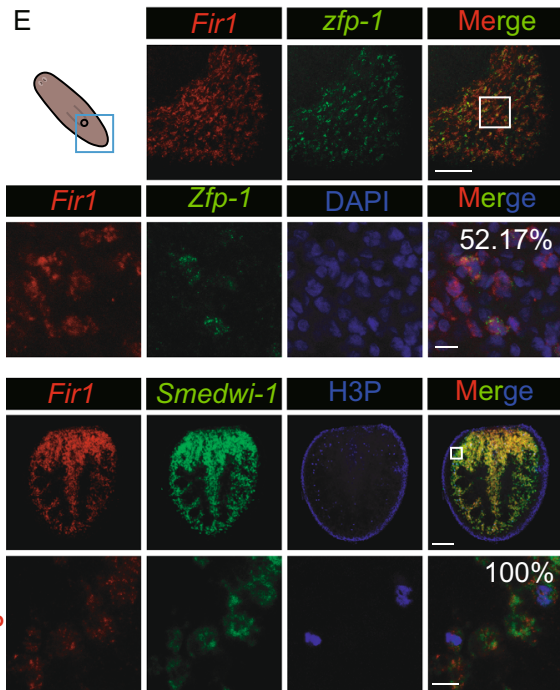

$52.17 \%$
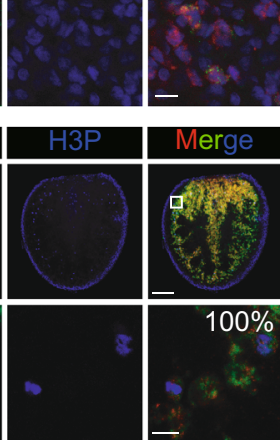

Figure 3. Fir1 mRNA is mainly expressed in neoblasts. (A) Colorimetric WISH of animals after 6,000 rads irradiation exposure showing that Fir1 mRNA levels were irradiation sensitive. For each condition, $n=10$ animals. Scale bars, $200 \mu m$. (B) Representative confocal projections (ten $1 \mu \mathrm{m}$ z-stacks) of planarian head, stained with Fir1 (red), smedwi-1 (green) and DAPI (blue). (B1) Head of the planarian. (B2) Zoom-in in the brain region. (B3) Zoom-in post brain. White arrowheads highlight Fir1 ${ }^{+}$smedwi-1- cells; yellow arrowheads point at double positive cells. The number indicates the percentage of Fir $1^{+}$cells co-expressing $s m e d w i-1$ ( $n>500$ cells). Ventral views, anterior up. Scale bars, B1: $100 \mu \mathrm{m}$; B2, B3: $10 \mu \mathrm{m}$. (C) Fir1 expression in neoblasts (referred to as X1 cells) sorted using FACS was detected using FISH. The number indicates the percentage of X1 cells expressing Fir1 ( $n>400$ cells). Scale bar, 10 $\mu \mathrm{m}$. (D) Double FISH of Fir1 (red) and soxP-2 (green) with DAPI (blue). Box indicates zoomed-in region. Ventral view of planarian tail. The number indicates the percentage of Fir $1^{+}$cells co-expressing soxP-2 ( $n>500$ cells). Scale bar, upper panel: $50 \mu \mathrm{m}$; lower panel: $10 \mu \mathrm{m}$. (E) Double FISH of Fir1 (red) and zfp-1 (green) with DAPI (blue). Box indicates zoomed-in region. Ventral view of planarian tail. The number indicates the percentage of Fir $1^{+}$cells co-expressing zfp-1 ( $n>500$ cells). Scale bar, upper panel: $50 \mu$ m; lower panel: $10 \mu \mathrm{m}$. (F) Representative confocal plane from macerated planarians subjected to a $4 \mathrm{~h}$ BrdU pulse and labeled by Fir1 and smedwi-1 FISH probes and BrdU IF. Pie chart quantifies the percentage of $\mathrm{BrdU}^{+}$cells labeled with Fir1 and smedwi-1 FISH probes $(n=519)$. Scale bar, $5 \mu \mathrm{m}$. (G) Colorimetric WISH of regenerating middle pieces for Fir1. Ventral views, for each time point, $n=10$ animals. Scale bars, $200 \mu \mathrm{m}$. (H) Representative confocal projections of tail pieces $48 \mathrm{~h}$ following amputation, labelled by Fir1 (red), smedwi-1 (green) and H3P antibody (blue). Box indicates zoomed-in region. The number indicates the percentage of $\mathrm{H}^{\mathrm{P}} \mathrm{P}^{+}$cells coexpressing Fir1 ( $n>100$ cells). Scale bars, upper panel: $100 \mu \mathrm{m}$; lower panel: $10 \mu \mathrm{m}$.

expression pattern during regeneration, we performed colorimetric WISH on 10 regeneration time points and found that like smedwi-2, Fir1 mRNA expression dramatically increased $48 \mathrm{~h}$ post-amputation especially near the wounds, suggesting that Fir1 may play important roles in this region (Figs. 3G and S3F). Further, we examined Fir1 mRNA, smedwi-1 mRNA and mitosis marker H3P in tail pieces $48 \mathrm{~h}$ post-amputation (Fig. $3 \mathrm{H}$ ). We observed that all $\mathrm{H}^{+} \mathrm{P}^{+}$cells expressed Fir1 mRNA as well as smedwi-1 mRNA, suggesting that Fir1 may regulate local proliferation during regeneration.

\section{Analysis of Fir1 downstream genes by screening}

Considering all the results discussed above, we hypothesized that Fir1 promotes regeneration by controlling 


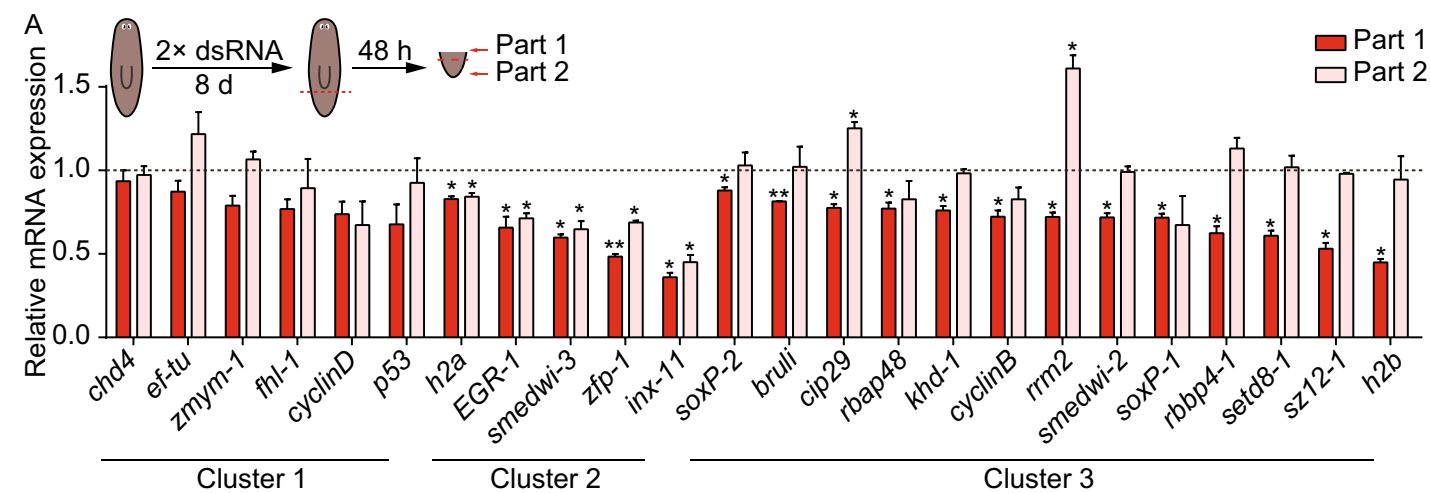

B

2× dsRNA feeding 8 days<smiles>C1CCCCC1</smiles>

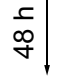

$\forall-$ Part 1

Microarrays

C
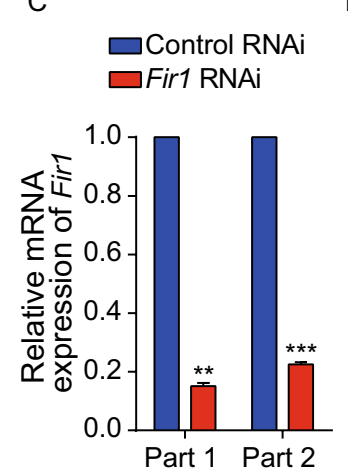

$\mathrm{F}$

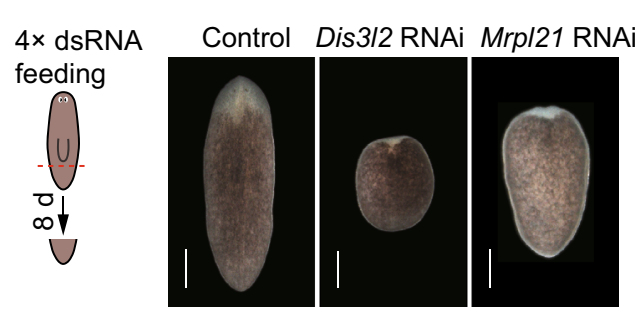

D

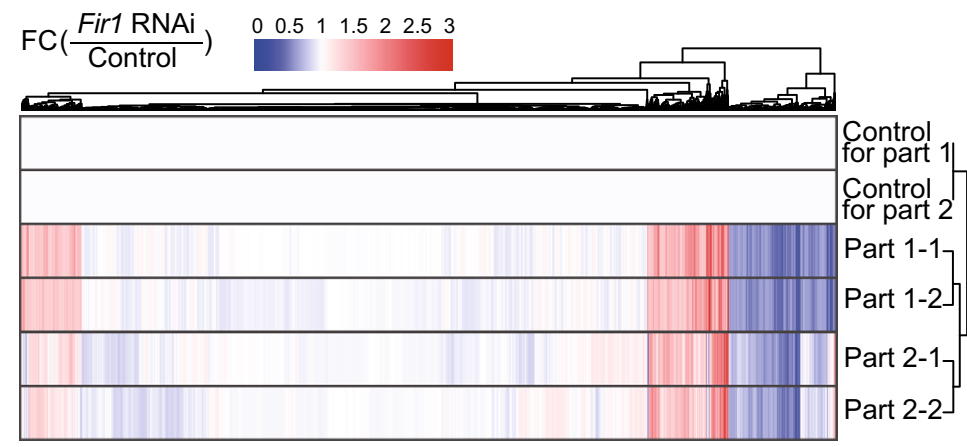

E

Part $1 \quad$ Part 2

$\mathrm{FC} \leq 0.5 \quad 0.8 \leq \mathrm{FC} \leq 1.2$

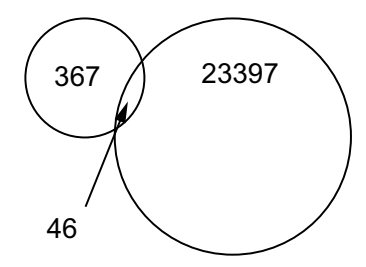

$\mathrm{H}$
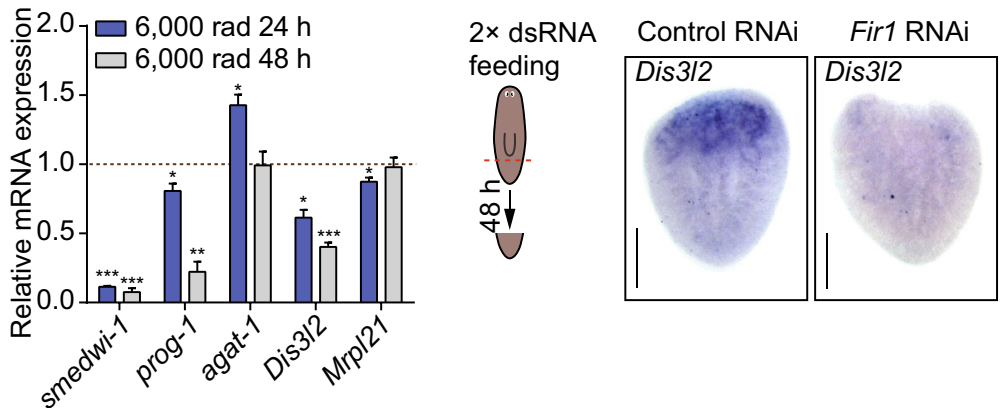

Figure 4. Analysis of Fir1 downstream genes. (A) qRT-PCR showing the relative mRNA expression of several known neoblast regulators following Fir1(RNAi). Shown are averages of three independent experiments; error bars $=\mathrm{SEM}$; ${ }^{* *}$ equals $P<0.001$; ${ }^{* * *}$ equals $P<0.0001$; significance determined with Student's $t$ test. (B) Schematic of strategy for expression profiling. (C) qRT-PCR showing that relative expression level of Fir1 decreased dramatically in part 1 and part 2 regions of Fir1(RNAi) tail pieces. Shown are averages of three independent experiments; error bars $=$ SEM; ${ }^{* *}$ equals $P<0.001$; ${ }^{* *}$ equals $P<0.0001$; significance determined with Student's $t$ test. (D) Heat map of microarrays. Fold change (Fir1 RNAi/control); (red) up, (blue) down; $P<0.05$. (E) Venn diagram of genes down-regulated in the part 1 region and invariable in the part 2 region in Fir1(RNAi) tail piece. (F) RNAi knockdown of two candidates (Dis3/2 and Mrp/21) respectively, tail pieces hardly regenerate blastemas $(n=6)$. To increase the RNAi efficiency, we chose $4 \times$ dsRNA feedings for the two genes. The animals were amputated behind the pharynx at the day after the fourth dsRNA feeding, and the tail pieces were imaged 8 days post-amputation. Scale bars, $200 \mu \mathrm{m}$. (G) Relative expression levels of smedwi-1, prog-1, agat-1, Dis3/2 and Mrp/21 mRNA in animals after 6,000 rads irradiation exposure. Error bars represent SEM; Student's $t$ test: * equals $P<0.05$, ${ }^{* *}$ equals $P<0.001$, ${ }^{* *}$ equals $P<0.0001$. (H) Colorimetric WISH of Fir1(RNAi) tail pieces 48 h post-amputation for Dis3/2. For each condition, $n=10$ animals. Scale bars, $200 \mu \mathrm{m}$.

regenerative proliferation. It is reported that many neoblast regulators could regulate planarian regeneration, we attempted to establish whether some known genes were related to the Fir1 function (Labbe et al., 2012; Onal et al., 2012; Wagner et al., 2012). We examined the fold change of some known neoblast regulators using qRT-PCR assay in 
part 1 and part 2 regions following Fir1(RNAi) and utilized these results to classify these genes into three clusters (Fig. 4A). Genes that were not affected by Fir1(RNAi) were assigned to Cluster one which contained chd4, ef-tu, zmym$1, f h l-1, c y c l i n D$ and $p 53$, and these genes were not referred to as Fir1 downstream genes. Genes that downregulated significantly in both part 1 and part 2 belonged to Cluster two, which contained $h 2 a$, egr-1, smedwi-3, zfp-1, and inx11. Although these genes were Fir1 downstream genes, they might not participate in regulating regenerative proliferation. Genes that downregulated significantly only in part 1 constituted Cluster three, which included soxP-2, bruli, cip29, rbap48, khd-1, cyclinB, rrm2, smedwi-2, soxP-1, rbbp4-1, setd8-1, sz12-1, and $h 2 b$. Genes in this cluster were supposed to be downstream genes of Fir1 controlling local proliferation. However, these genes did not pheno-copy Fir1 upon RNAi, suggesting that Fir1 might downregulate other new genes to drive local proliferation (Figs. 1B-D and S1B, data not shown).

In other species, the homologous of FIR1 protein is POGZ (pogo transposable element-derived protein with zinc finger domain), which is poorly understood in stem cell research (Fig. S4A). FIR1 protein was predicted to contain 6 $\mathrm{ZnF}{ }_{-} \mathrm{C}_{2} \mathrm{H}_{2}$ domains from SMART, suggesting that FIR1 may function as a transcription factor (Fig. S4B). We sought to define the molecular mechanism of FIR1 by expressionprofiling experiments. We designed custom oligonucleotide microarrays representing 61,657 predicted S. mediterranea transcripts and isoforms from various sources (Kao et al., 2013; Labbe et al., 2012; Onal et al., 2012; Rouhana et al., 2012; Wenemoser et al., 2012). Based on our observations that mitoses decreased dramatically at the wound sites (part 1) while increasing significantly in the remaining Fir1(RNAi) tail pieces (part 2) $48 \mathrm{~h}$ post-amputation, we isolated 'part 1' and 'part 2' tissues for microarrays (Fig. 4B). Prior to microarray analysis, we first examined the Fir1 knockdown efficiency using qRT-PCR assay and found that Fir1 mRNA expression decreased dramatically in both part 1 and part 2 (Fig. 4C). To display an overview of the microarray results, we clustered the transcripts according to fold change using $R$ language, which revealed that the expression level of most transcripts did not change in either part 1 or part 2 (Fig. 4D). In addition, we checked the fold change of several known neoblast regulators and found that 25/34 of these genes showed the similar fold change as our qRT-PCR results (Figs. S4C and 4A, data not shown). According to the criterion for assignment to Cluster three above, we identified 46 genes the expression of which decreased more than $50 \%$ in part 1 and had no change in part 2 in our microarrays (Fig. 4E, Table S3). Further, considering the possible function of gene orthologs, we finally chose 26 genes for RNAi analysis, and to find more genes promoting regeneration, we increased the dsRNA feeding times to 4. Finally, we found that only Dis3/2(RNAi) and Mrp/21(RNAi) animals exhibited regeneration defects, suggesting that these two genes might function as Fir1 downstream genes (Fig. 4F).

\section{Fir1 functions through regulation of Dis $3 / 2$}

To establish that either Dis3/2 or Mrp/21 functions as a Fir1 downstream gene, we detected the mRNA expression of Dis3/2 and Mrp/21 by qRT-PCR in animals irradiated for $24 \mathrm{~h}$ and $48 \mathrm{~h}$. The expression of Mrp/21 was not reduced in animals irradiated for $48 \mathrm{~h}$, indicating that Mrp/21 was not expressed in neoblasts. In the previous study, Fir1 was predominantly expressed in neoblasts and could control local neoblast proliferation. So, we considered that Mrp/21 was not a direct downstream gene of Fir1. Interestingly, we found that Dis $3 / 2$ mRNA expression reduced dramatically, with $50 \%$ reduction noted in samples irradiated for $48 \mathrm{~h}$, indicating that Dis3/2 was expressed in neoblasts (Fig. 4G). Planarian DIS3L2 was similar to Drosophila DIS3L2 in protein sequences and, like DIS3L2 in other organisms, it may be involved in proliferation regulation (Fig. S4D). Further, we examined Dis3/2 mRNA expression in tail pieces regenerated for $48 \mathrm{~h}$ following Fir1(RNAi). We found that the Dis $3 / 2$ mRNA expression decreased at the wound sites, suggesting that Fir1 may promote Dis3/2 expression during regeneration (Fig. 4H).

Since the colocalization of Fir1 and Dis $3 / 2$ is a prerequisite of the hypothesis that Fir1 controls local proliferation through Dis3/2, Dis $3 / 2^{+}$Fir $1^{+}$cells should exist at the wound sites. To ascertain whether Fir1 mRNA and Dis3/2 mRNA were colocalized at the wound sites, we conducted dFISH with Fir1 and Dis3/2 probes in tail pieces that have been regenerating for $48 \mathrm{~h}$ and noted that $61.5 \%$ of Dis $3 / 2^{+}$cells also expressed Fir1 mRNA at the wound sites (Fig. 5A). We also examined the expression pattern in intact animals, and we observed that Dis3/2 was expressed in the planarian parenchyma, suggesting that Dis $3 / 2$ may participate in neoblast regulation (Fig. S5A). Importantly, we detected the proliferation in Dis3/2(RNAi) tail pieces $48 \mathrm{~h}$ post-amputation and found that Dis3/2(RNAi) tail pieces displayed reduced mitoses at the wound sites only (Fig. 5B and 5C). To explore the delicate change of mitoses in Dis3/2(RNAi) tail pieces, we quantified the mitotic density from the wound sites and found that Dis3/2(RNAi) tail pieces displayed reduced mitotic neoblasts in the region $250 \mu \mathrm{m}$ away from the wounds, which is wider than that of in Fir1(RNAi) tail pieces, suggesting that Dis3/2 may promote local proliferation more extensively (Figs. S1D and S5B). Further, we examined neoblast lineage markers (neoblast marker smedwi-1, neoblast early progeny marker prog-1 and neoblast late progeny marker agat-1) in Dis3/2(RNAi) tail pieces $48 \mathrm{~h}$ post-amputation. We observed that the number of smedwi- $1^{+}$cells reduced, while the number of prog $-1^{+}$and agat $-1^{+}$cells at the wound sites did not change compared to control animals (Fig. 5D). The expression of Dis $3 / 2$ is reduced near the wound in Fir1(RNAi) tail pieces $48 \mathrm{~h}$ post-amputation, meanwhile, the accumulation of smedwi- $1^{+}$cells in the same region also disappeared (Fig. S5C). These results suggest that Dis $3 / 2$ as a downstream gene of Fir1 is required for local proliferation. 
A

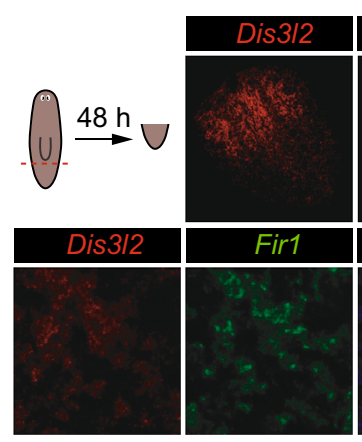

D
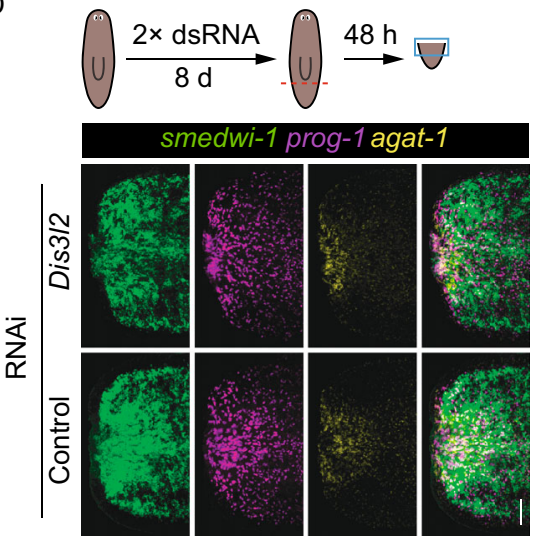
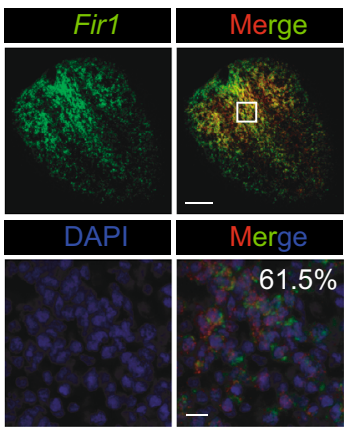

E

E

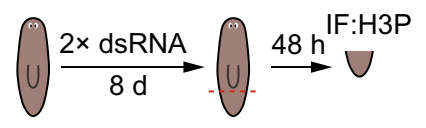

Control RNAi Dis3/2 RNAi
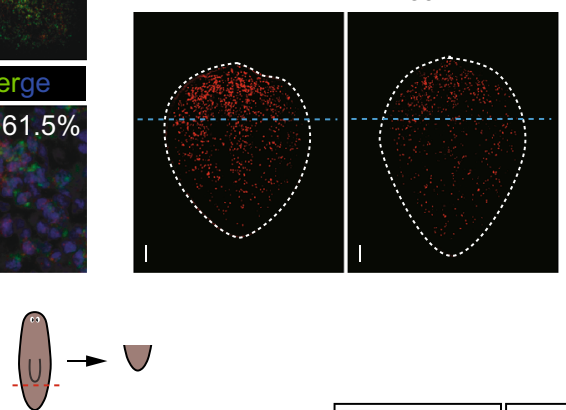

C

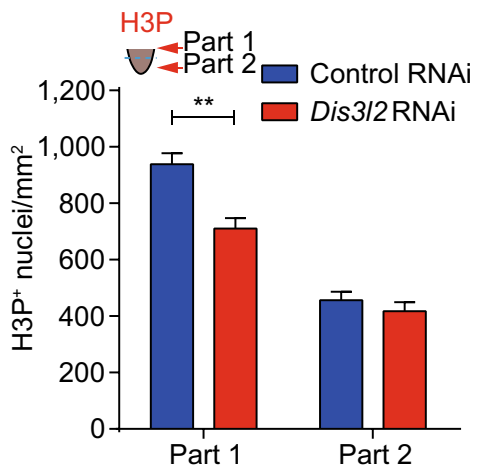

Figure 5. Fir1 functions through regulation of Dis3/2. (A) Representative confocal projections through wildtype tail pieces fixed 48 h post-amputation, labelled with Dis3/2 (red), Fir1 (green) and DAPI (blue). Box indicates zoomed-in region. The number indicates the percentage of Dis $3 / 2^{+}$cells co-expressing Fir1 ( $n=561$ cells). Ventral view; scale bar, upper panel: $50 \mu \mathrm{m}$; lower panel: $10 \mu \mathrm{m}$. (B) Representative confocal projections through tail pieces fixed $48 \mathrm{~h}$ post-amputation following RNAi administration, stained with H3P antibody. Dotted lines (white): tail piece boundary. Scale bars, $100 \mu \mathrm{m}$. Dotted lines (blue) separate the tail pieces into two parts for quantification in (C). (C) Mitotic density in part 1 and part 2 as separated in (B). Error bars represent SEM; ${ }^{* *}$ equals $P<0.001$; significance determined by Student's $t$ test. (D) The neoblast population adjacent of the wound sites reduced in Dis3/2(RNAi) tail pieces as assayed with neoblast lineage markers (smedwi-1 for neoblast, prog-1 for neoblast early progeny and agat-1 for neoblast late progeny). Scale bars, $100 \mu \mathrm{m}$. (E) Colorimetric WISH of intact animals and regenerating middle pieces for Dis $3 / 2$. For each time point, $n=6$ animals. Scale bars, $200 \mu \mathrm{m}$.

To further validate this assertion, we examined the expression pattern of Dis3/2 mRNA by colorimetric WISH in intact animals and regenerating tails. We observed that the expression of Dis3/2 mRNA at the wound sites increased from $18 \mathrm{~h}$ to 2 days post-amputation with quite a low expression in intact worms, indicating that Dis $3 / 2$ was induced by tissue-missing injury (Fig. 5E). Taken together, these data suggest that Fir1 drive local proliferation, at least partially, by promoting Dis3/2 expression.

\section{Fir1 is required for neoblast wound recognition during regeneration initiation}

Fir1 mRNA is mainly expressed in neoblasts that are distributed throughout the animal body, whereas, Fir1 could control the local proliferation in regeneration. To address this question, we focused on the roles of Fir1 in wound response to tissue absence. It is reported that many genes could be induced post-amputation, and are classified into four categories (W1, W2, W3 and W4) (Wenemoser et al., 2012). After the injury, W1 genes are activated within $30 \mathrm{~min}$ to $1 \mathrm{~h}$ and reach maximum expression by $3 \mathrm{~h}$, and W2 and W3 genes are induced within $3 \mathrm{~h}$ to $12 \mathrm{~h}$ with expression peaking at $6 \mathrm{~h}$. W2 genes are mostly expressed subepidermally at the wound sites, and W3 gene expression, in contrast, occurs in the epidermis far from wounds. W1, W2 and W3 genes are induced in differentiated tissues, while W4 genes are up-regulated in neoblasts. We first examined the mRNA expression of runt-1 belonging to W4, which were highly induced in neoblasts 3-6 h post-amputation and observed that Fir1(RNAi) trunk pieces displayed significantly reduced runt $-1^{+}$cells, suggesting that Fir1(RNAi) reduced the wound recognition capacity of neoblasts (Fig. 6A). We also examined another W4 gene, cdc25-1, in Fir1(RNAi) head pieces 6 

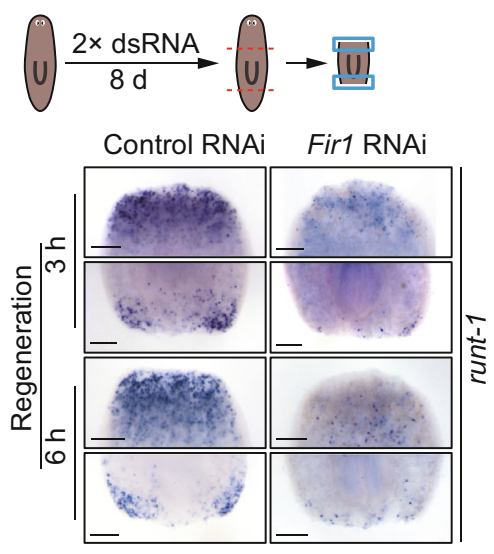

D

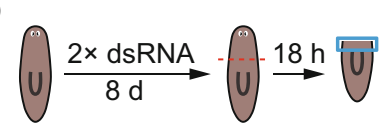<smiles>C1CC1[Hg]C1CC1</smiles>

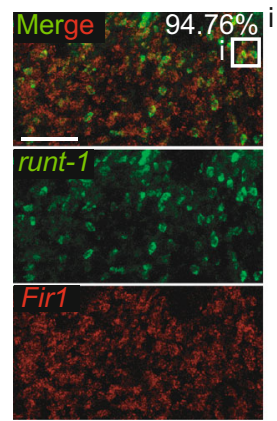

E
C
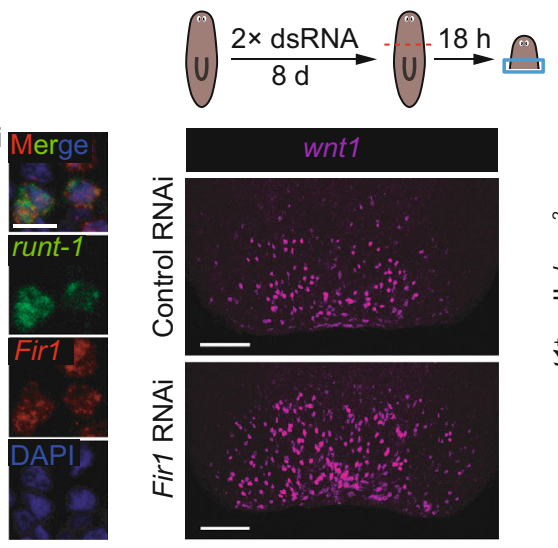

$\mathrm{F}$

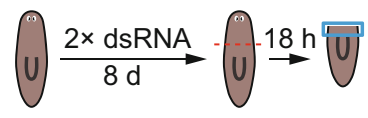

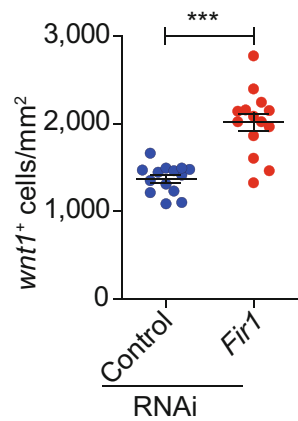

F

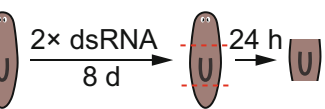

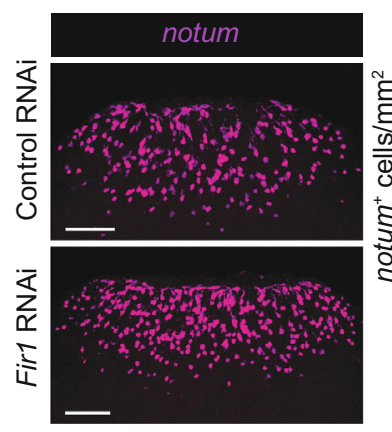
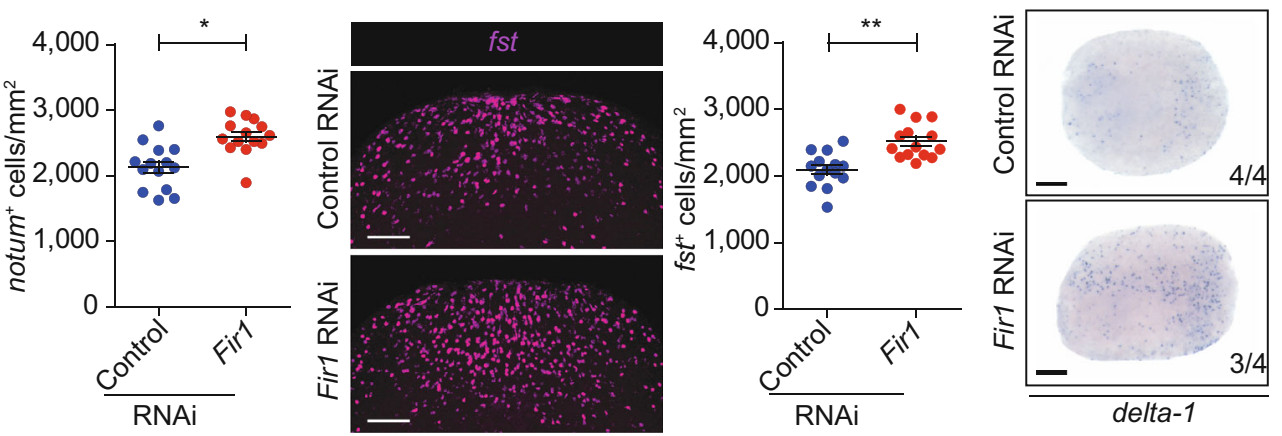

Figure 6. Fir1 is required for neoblast wound recognition during regeneration initiation. (A) Fir1(RNAi) trunk pieces displayed reduced runt $-1^{+}$cells at the wound sites $3 \mathrm{~h}$ and $6 \mathrm{~h}$ after amputation $(n=10 / 10)$. (B) Representative confocal projections through trunk pieces fixed $3 \mathrm{~h}$ post-amputation, labelled with runt-1 (green), Fir1 (red) and DAPI (blue). The images shown indicate the region near the anterior wound site. Box indicates zoomed-in region. The number indicates the percentage of runt- $1^{+}$cells co-expressing Fir1 ( $n=210$ cells). Ventral view; scale bar, upper panel: $50 \mu \mathrm{m}$; lower panel: $10 \mu \mathrm{m}$. (C) Fir1(RNAi) head pieces displayed increased wnt $1^{+}$cells at the wound sites $18 \mathrm{~h}$ after amputation $\left(P<0.0001\right.$, two-tailed $t$ test). (D) Fir1(RNAi) animals displayed increased notum ${ }^{+}$ cells at the wound sites $18 \mathrm{~h}$ following head amputation ( $P<0.05$, two-tailed $t$ test). (E) Fir1(RNAi) animals displayed increased $f s t^{+}$ cells at the wound sites $18 \mathrm{~h}$ following head amputation ( $P<0.001$, two-tailed $t$ test). (F) Fir1(RNAi) animals increased wound-induced expression of delta-1 $24 \mathrm{~h}$ after amputation $(n=3 / 4)$. Scale bars, (A, C, D and E) $100 \mu \mathrm{m}$, (B and F) $200 \mu \mathrm{m}$.

h post-amputation, and found that no evidence of cdc25-1 expression at the wound sites, which confirmed the assertion made above (Fig. S6A, arrowheads). Furthermore, we examined Fir1 and runt-1 expression pattern in animals $3 \mathrm{~h}$ post-amputation and found that $94.76 \%$ runt $-1^{+}$cells expressed Fir1 (Fig. 6B). These results suggest that Fir1 is required for neoblast wound response.

Moreover, we explored genes belonging to W1, W2 and W3 in Fir1(RNAi) regenerating pieces. The mRNA expression of W1 genes like jun-1 and egrl-1 decreased 1-3 h postamputation in Fir1(RNAi) animals (Fig. S6B and S6C). Notably, amputated Fir1(RNAi) animals displayed a higher level of expression of some W2 genes (wnt1, notum and fst) than did controls $18 \mathrm{~h}$ after amputation, suggesting that the regenerative signals were blocked (Fig. 6C-E). The expression of some W3 genes, such as delta-1, also increased $24 \mathrm{~h}$ post-amputation in Fir1(RNAi) animals (Fig. 6F). To further explore whether the regeneration was initiated after Fir1(RNAi), we detected the expression pattern of wnt1 and notum $48 \mathrm{~h}$ post-amputation in Fir1(RNAi) animals. We observed that Fir1(RNAi) animals did not establish anterior-posterior polarity, suggesting that regenerative procedure could not be activated following Fir1(RNAi) (Fig. S6D).

On the other hand, wound activates apoptosis, which could induce proliferation and provide a wounding signal in 
A
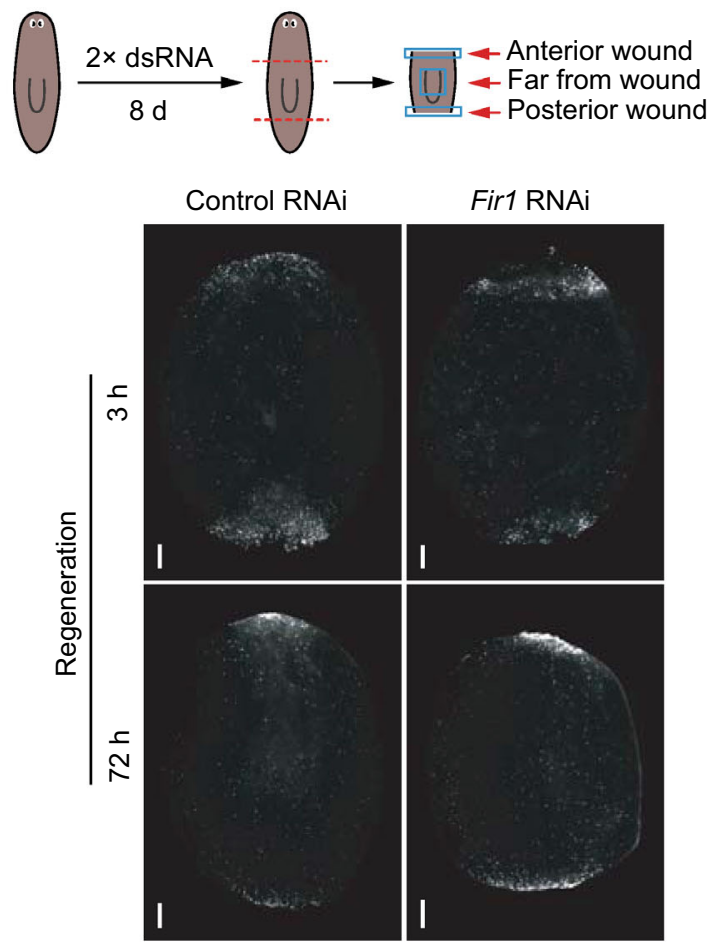

B

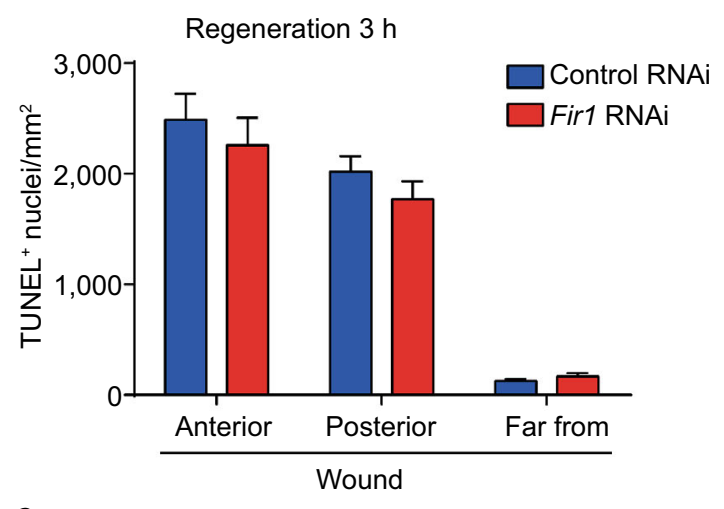

C

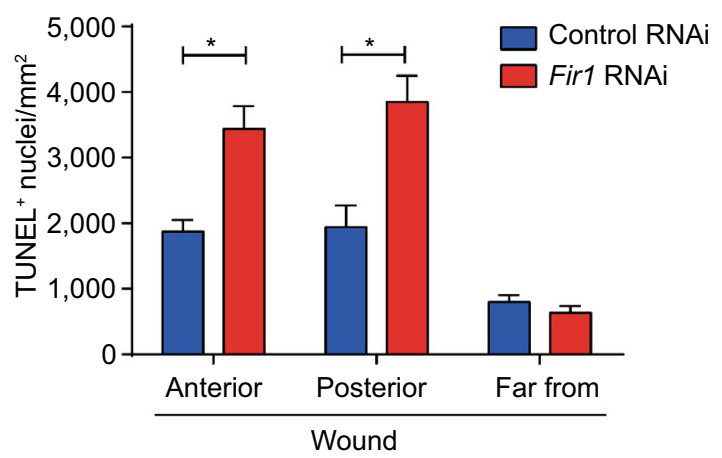

Figure 7. Fir1(RNAi) animals display abnormal apoptotic pattern during regeneration. (A) The apoptosis in Fir1(RNAi) trunk pieces $3 \mathrm{~h}$ and $72 \mathrm{~h}$ post-amputation $(n=8 / 8)$. Scale bars, $200 \mu \mathrm{m}$. (B and C) Quantification of TUNEL ${ }^{+}$cells at anterior, posterior and far from wound in Fir1(RNAi) trunk pieces $3 \mathrm{~h}$ and $72 \mathrm{~h}$ post-amputation respectively. Error bars represent SEM; Student's $t$ test: * equals $P<0.05$.

tissue repair (Fuchs and Steller, 2015). In planarians, apoptosis increases following injury and this increase involves a generic injury phase and a missing-tissue-specific phase. A local apoptosis burst initially occurs at the wound sites $3 \mathrm{~h}$ following any injury, and is followed by a body-wide apoptosis burst that commences $72 \mathrm{~h}$ after the injury, but only in cases involving missing tissue (Gavino et al., 2013; Pellettieri et al., 2010). To check if the apoptosis in response to amputation was normal during planarian regeneration, we measured apoptosis $3 \mathrm{~h}$ and $72 \mathrm{~h}$ post-amputation in Fir1 (RNAi) animals by TUNEL. The Fir1(RNAi) animals displayed the same apoptosis pattern as the controls $3 \mathrm{~h}$ postamputation, indicating that apoptosis for wound response was not affected by Fir1(RNAi) (Fig. 7A and 7B). Strikingly, $72 \mathrm{~h}$ post-amputation, a greater number of cells undergoing apoptosis at the wound sites was noted in Fir1(RNAi) animals compared to the controls, suggesting that regeneration did not initiate upon Fir1(RNAi) (Fig. 7A and 7C). When considered jointly, these results suggest that neoblasts at the wound sites could not recognize the regenerative signals and initiate regeneration in Fir1(RNAi) animals after amputation.

\section{DISCUSSION}

The proliferation of adult stem cell in regeneration

In mammals, the proliferation of adult stem cells is essential for tissue/organ regeneration. For example, cardiomyocyte proliferation is critical for heart regeneration in neonatal mice (Porrello et al., 2011), and intestinal stem cell proliferation, regulated by Hippo pathway, plays an important role during Drosophila adult midgut regeneration (Shaw et al., 2010). Inhibition of cell proliferation blocks the regeneration of oral structures in the anthozoan cnidarian (Passamaneck and Martindale, 2012). In planarians, regeneration is mediated by neoblasts, the only dividing cells, which are responsible for tissue regeneration (Wagner et al., 2011). Planarian can regenerate any part of the body rapidly, which makes them an ideal model for studying stem cell function in vivo (Gentile et al., 2011; Sanchez Alvarado, 2003). After amputation, two phases of proliferation occur: the first is initiated after all kinds of injury, while the second is triggered only when regeneration is required (Wenemoser and Reddien, 2010). The second phase of proliferation is restricted to the wounds (also known as local proliferation), which is equivalent to the 
A
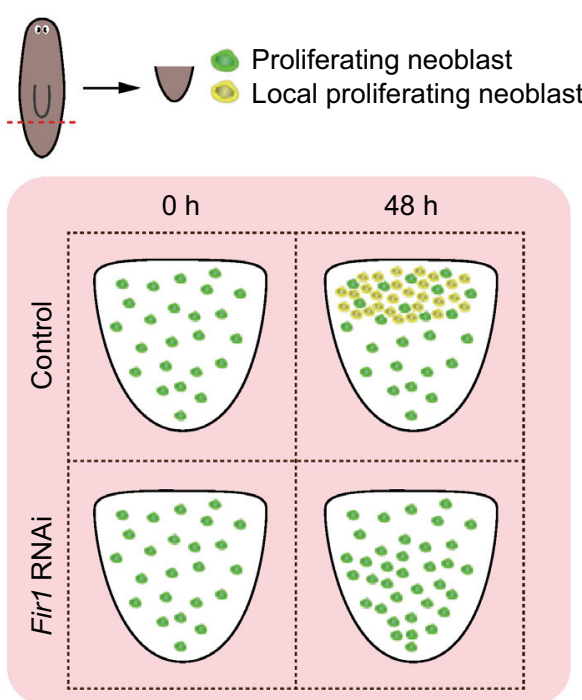

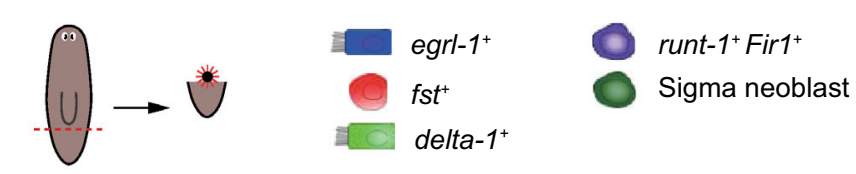

潾 Wound signal

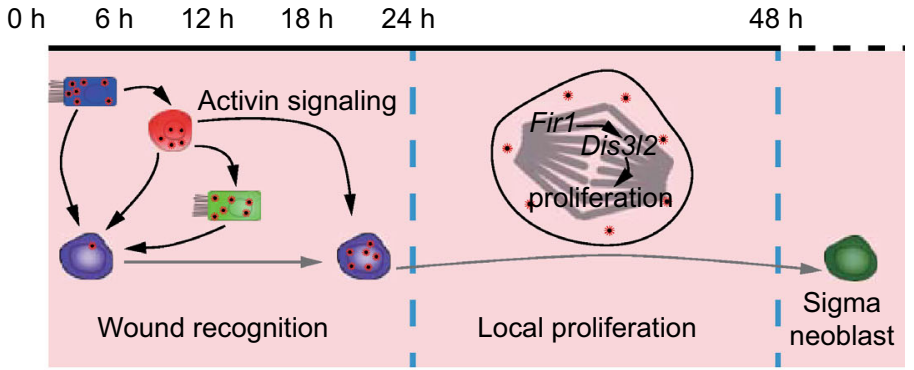

Figure 8. Model of Fir1 mechanisms in regeneration. (A) Model of Fir1 function in regeneration. Fir1, a neoblast-enriched regulator, controls regenerative proliferation. (B) A proposed genetic model for Fir1 in regeneration. Once a missing-tissue injury occurs, Fir $1^{+}$cells at the wound sites acquire wound and regenerative signal, sense regeneration on demand. Then Fir1 promotes the expression of Dis3/2, which triggers local proliferation, and generate sufficient neoblast for sequential regeneration.

proliferation of adult stem cells for tissue/organ regeneration in mammals.

\section{Neoblast-enriched Fir1 triggers local neoblast proliferation}

To find neoblast intrinsic regulators required for local neoblast proliferation, we analyzed the regeneration phenotypes, the mitotic activity and the percent of neoblasts after inhibiting each of the 46 genes that were selected according to the severity of RNAi phenotypes and neoblast-enriched features reported in pertinent literature, as well as found in our proprietary database (Figs. S1B and 1B-D, Table S1). Despite the small size of our screening, we found that $a$ novel gene Fir1 meets our requirements exactly. First, Fir1 (RNAi) trunk pieces cannot regenerate blastemas (Figs. S1B and $2 \mathrm{~A}$ ). Second, Fir1(RNAi) tail pieces display reduced mitotic activity near the wounds $48 \mathrm{~h}$ post-amputation (Fig. 1B and 1C). Third, the percent of neoblasts was indistinguishable from that found in the control animals (Fig. 1D). Moreover, almost all Fir1 ${ }^{+}$cells express smedwi-1 (Fig. 3B). In our screening, we chose regenerating tail pieces, in which nearly all Fir ${ }^{+}$cells express smedwi-1, as the main model for screening genes required for local proliferation (Fig. 3H, data not shown). Therefore, these results suggest that Fir1 may function as a neoblast intrinsic regulator controlling local proliferation. To date, many genes are reported to be required for neoblast proliferation during regeneration, such as smedwi-2 (Reddien et al., 2005b),
Smed-hp1-1 (Zeng et al., 2013), Smed-argonaute-2 (Li et al., 2011) and Smed-p53 (Pearson and Sanchez Alvarado, 2010). However, most of these genes regulate proliferation of all the neoblast throughout animal body, and it is presently unknown if there exist neoblast intrinsic regulators specifically required for local proliferation responsible for a missingtissue injury. Here, for the first time, we identified neoblastenriched gene Fir1 required for local proliferation, which provided in vivo mechanisms for adult stem cell proliferation during regeneration.

\section{Dis3/2 is a potential target of Fir1}

FIR1 protein is predicted to contain $6 \mathrm{ZnF}_{-} \mathrm{C}_{2} \mathrm{H}_{2}$ domains, which suggests that Fir1 may function as a transcription factor. To find genes downstream of Fir1 in regulating local proliferation, we mainly analyzed the downstream transcripts adjacent to the wounds after RNAi knockdown of Fir1 by microarray. Indeed, the best way is isolating the neoblasts near the wounds to perform expression-profiling experiments. But we could not get enough neoblasts for microarray, and that is why we chose tissues near the wounds for microarray analysis instead. Although the expression of some reported neoblast regulators decreased dramatically, these genes did not affect the local proliferation required for regeneration as we expected, indicating that Fir1 is one of the few genes involved in this process. Importantly, we identified a novel gene Dis3/2 as a potential target of Fir1. First, Dis3/2 is downregulated after RNAi knockdown of Fir1 
and promotes planarian regeneration (Fig. 4F and $4 \mathrm{H}$ ). Second, Dis3/2 is expressed in neoblasts and colocalizes with Fir1 in the vicinity of wound $48 \mathrm{~h}$ post-amputation (Figs. 4G and 5A). Intriguingly, colorimetric WISH reveals that rare Dis3/2 mRNA is detected in intact animals, while Dis3/2 mRNA is induced adjacent to the wounds from $18 \mathrm{~h}$ post-amputation with obvious accumulation following $48 \mathrm{~h}$ of regeneration (Fig. 5E). Moreover, Dis3/2 mRNA disappears in this region as regeneration progresses, which suggests that Dis3/2 mRNA dynamics are consistent with its function during regeneration (Fig. 5E). Most importantly, Dis3/2 is required for local proliferation, suggesting that Dis $3 / 2$ may be a functional downstream gene of Fir1 (Fig. 5B and 5C). Dis3/2, mutations in which cause the Perlman syndrome, is a member of a highly conserved family of exoribonucleases that degrade RNA in a $3^{\prime}-5^{\prime}$ direction (Astuti et al., 2012). Dis3/2 plays a critical role in RNA metabolism and is essential for the regulation of cell growth and division. For example, Dis3/2 functions in the Lin28-mediated repression and degradation of let-7 microRNAs (miRNAs) in mouse embryonic stem cells (mESCs) (Chang et al., 2013; Ustianenko et al., 2013). Knockdown of Dis3/2 enhances the growth of human cancer cell lines (Astuti et al., 2012). However, in planarian, inhibition of Dis3/2 suppresses the local proliferation required for regeneration, suggesting that Dis3/2 may degrade the mRNA transcribed by genes inhibiting neoblast proliferation adjacent to the wounds during regeneration.

\section{Neoblast response to injury requires Fir1 function}

In planarians, three major classes of wound-induced genes that are expressed in differentiated tissues (W1, W2 and W3 genes) and a class of genes induced in neoblasts (W4 genes) have been identified, which constitute a molecular wound response program to elicit regeneration (Wenemoser et al., 2012). We examined the expression pattern of representative genes in four categories following Fir1 RNAi and found that the response of these genes to amputation displayed abnormally. The induction of W4 genes (runt-1 and cdc25-1) and W1 genes (jun-1 and egrl-1) was reduced in Fir1(RNAi) animals, while the induction of W2/3 genes like wnt1, notum, fst, and delta-1 increased significantly (Figs. 6A, 6C-F and S6A-C), suggesting that Fir1 is required for wound response during regeneration. It is reported that $f s t$, a wound-induced gene expressed in differentiated tissues, is required for local mitosis by inhibiting Activin signaling (Gavino et al., 2013). The increase in the number of $\mathrm{fst}^{+}$cells near wounds can be explained as the interruption of regenerative signals before neoblasts sensing them. Moreover, a recent study has revealed that neoblasts express most wound-induced genes, suggesting that neoblasts may play an important role in wound response (Wurtzel et al., 2015). Here, we for the first time identified Fir1 as a potential neoblast intrinsic regulator controlling neoblast response to missing-tissue injury.

\section{MATERIALS AND METHODS}

Planarian culture and irradiation

In this study, sexual Schmidtea mediterranea CIW4 strain was used in all experiments. These planarians were maintained as described elsewhere (Newmark and Sanchez Alvarado, 2000; Sanchez Alvarado et al., 2002; Wang et al., 2016). Briefly, planarians were cultured in $1 \times$ Montjuic salts at $21^{\circ} \mathrm{C}$ in the dark, fed homogenized beef liver paste two times per week, and amputated for expansion. Planarians were starved for 1-2 weeks before experiments. 4-6 $\mathrm{mm}$-long animals were used for RNAi and 1-2 mm-long animals were used for in situ hybridization. For irradiation, planarians were exposed to 6,000 rads on a GammaCell 3000 irradiator (Table S4). The animals were kindly provided by P. Newmark (University of Illinois at Urbana-Champaign/Howard Hughes Medical Institute, Urbana, IL), P. Reddien (Massachusetts Institute of Technology/ Howard Hughes Medical Institute, Cambridge, MA), and N. Oviedo (University of California, Merced, Merced, CA).

\section{Gene cloning and RNAi}

All planarian transcripts used in this study were cloned into the pMD18-T vector (Takara) from complementary DNA (cDNA) and verified by Sanger sequencing. RNA interference (RNAi) was mainly performed as described elsewhere (Rouhana et al., 2013). The template for producing dsRNA was generated by polymerase chain reaction (PCR) using primers with T7 promoters flanking on the 5'ends. The sense and antisense RNA molecules were transcribed by T7 RNA polymerase (Promega) and annealed. The quality of dsRNA was assessed by non-denaturing agarose gel electrophoresis. $4 \mu \mathrm{g}$ dsRNA with $20 \mu \mathrm{L}$ beef liver was sufficient for inducing 15 animals RNAi. dsRNA for GFP was used as negative control. Generally, animals were fed dsRNA food every 3 days, and the animals were amputated 8 days after initial RNAi. We made a cartoon depicting experiment design for each figure, which described the number of RNAi treatments, time of amputations after initial RNAi, amputation position (as indicated with dotted red lines) and time of detection. For RNAi of Dis $3 / 2$ and Mrp/21 in Fig. 4F, animals got $4 \times$ dsRNA feedings. Unless otherwise noted, animals were fed $2 \times$ dsRNA food (Table S2).

\section{Whole-mount immunofluorescence}

Whole-mount immunofluorescence was performed as described elsewhere (Newmark and Sanchez Alvarado, 2000; Wenemoser and Reddien, 2010). Briefly, animals were sacrificed and fixed in Carnoy's on ice for $1.5 \mathrm{~h}$, following bleaching in $6 \%$ hydrogen peroxide/methanol solution, animals were blocked and incubated with rabbit anti-H3P antibody (1:100, Millipore), and the mitotic activity was developed using anti-rabbit Alexa 488 (1:600, Invitrogen).

Immunofluorescence on paraffin section

Tail pieces following 2 days regeneration were fixed in $4 \%$ formaldehyde for $2 \mathrm{~h}$ at $4^{\circ} \mathrm{C}$. They were subsequently embedded in paraffin and sectioned adjacent to the wounds at $5 \mu \mathrm{m}$ thickness. After deparaffination, antigen retrieval was performed in $0.01 \mathrm{~mol} / \mathrm{L}$ citrate buffer, $\mathrm{pH} 6.0$, for $20 \mathrm{~min}$. Then the sections were blocked with 4\% BSA and incubated in HP1-1 (1:100 dilution) and SMEDWI- 
1 (1:200 dilution) antibody solution (Zeng et al., 2013). HP1-1 and SMEDWI-1 were developed using rhodamine tyramide $(1: 2,000$ dilution) and fluorescein tyramide (1:1,000 dilution), respectively. Horseradish peroxidase enzyme was inactivated for $20 \mathrm{~min}$ between labelings by $1 \%$ Hydrogen peroxide, in PBS containing $0.1 \%$ TritonX100 (PBSTx). The sections were counterstained with DAPI (sigma, $1 \mu \mathrm{g} / \mathrm{mL})$.

\section{Whole-mount in situ hybridization}

Whole-mount in situ hybridizations were performed as described elsewhere (Pearson et al., 2009). Hybridized RNA probes were labeled with DIG-11-UTP (Sigma), Fluorescein-12-UTP (Sigma) or DNP-11-UTP (Perkin Elmer) and purified as described (Lapan and Reddien, 2011). Tyramide was generated by conjugation of succinimidyl esters of rhodamine, FITC, and AMCA with tyramide-HCL (Sigma) (Hopman et al., 1998). For horseradish peroxidase enzyme inactivation, animals were incubated in $154 \mathrm{mmol} / \mathrm{L}$ sodium azide for 2 h (King and Newmark, 2013; van Wolfswinkel et al., 2014). Animals were counterstained with DAPI (Sigma, $3 \mu \mathrm{g} / \mathrm{mL}$ in PBSTx) for $1 \mathrm{~h}$ and mounted for imaging.

\section{Fluorescence-activated cell sorting}

The procedures of fluorescence-activated cell sorting were mainly performed as described elsewhere (van Wolfswinkel et al., 2014). Planarians were diced with a razor blade on ice-cold dishes, and the tissue mash was collected in CMFB $\left(400 \mathrm{mg} / \mathrm{L} \mathrm{NaH} \mathrm{NaO}_{2} \mathrm{PO} 800 \mathrm{mg} / \mathrm{L}\right.$ $\mathrm{NaCl}, 1,200 \mathrm{mg} / \mathrm{L} \mathrm{KCl}, 800 \mathrm{mg} / \mathrm{L} \mathrm{NaHCO}_{3}, 240 \mathrm{mg} / \mathrm{L}$ glucose, $1 \%$ BSA, $15 \mathrm{mmol} / \mathrm{L}$ HEPES pH7.3) supplemented with $1 \mathrm{mg} / \mathrm{mL}$ collagenase (Sigma) (Reddien et al., 2005a). After digestion for $45 \mathrm{~min}$ under agitation at room temperature, cell suspensions were passed through a $35 \mu \mathrm{m}$ cell-strainer cap (BD Biosciences), and pelleted. Then the cells were stained with Hoechst 33342 (Invitrogen) and propidium iodide and filtered again. Cells were sorted on a MoFlo (Beckman-Coulter), and Hoechst blue versus red plots were used to identify the ' $\mathrm{X} 1$ ' fraction that is high in DNA content (Hayashi et al., 2006).

\section{BrdU labeling}

BrdU labeling was performed as described elsewhere (Cowles et al., 2012). Briefly, animals were treated with $0.0625 \% \mathrm{~N}$-acetyl cysteine (NAC) for $1 \mathrm{~min}$, washed 3 times quickly, and incubated for $1 \mathrm{~h}$ in $1 \times$ Montjuïc salts containing $25 \mathrm{mg} / \mathrm{mL}$ BrdU (Sigma) and 3\% dimethyl sulfoxide in the dark. Animals were washed 3 times and inculcated for $4 \mathrm{~h}$ in the dark.

\section{Single-cell FISH and immunofluorescence on cells}

Cells from macerated animals or fluorescence-activated cell sorting were adhered to coverslips. Single-cell FISH was performed as described elsewhere (Scimone et al., 2014). For BrdU immunofluorescence after $\mathrm{FISH}$, the procedures were similar to that in whole mount animals, with slight modifications: all washes were limited to 5 min, and the BrdU signal was developed using rhodamine tyramide (Newmark and Sanchez Alvarado, 2000).

\section{qRT-PCR}

qRT-PCR was performed as previously described (Li et al., 2011; Wang et al., 2016; Zeng et al., 2013). Briefly, total RNA of the regenerating pieces was isolated using TRIZOL (Invitrogen). M-MLV Reverse Transcriptase (Promega) was used to synthesize cDNA from $1 \mu \mathrm{g}$ of total RNA. Gene-specific primers were designed using Primer3 (http://frodo.wi.mit.edu/primer3/) (Table S2). qPCRs were performed with SYBR Green quantitative PCR master mix (Toyobo Co.) on a quantitative PCR system (7900HT Fast Real-Time PCR System, Applied Biosystems). Three biological replicates were performed for each group. The relative mRNA expression was plotted with GraphPad Prism.

\section{Microarray analysis}

We designed custom oligonucleotide microarrays representing 61,657 predicted S. mediterranea transcripts and isoforms from various sources (Kao et al., 2013; Labbe et al., 2012; Onal et al., 2012; Rouhana et al., 2012; Wenemoser et al., 2012) at the eArray website (Agilent Technologies). 'part 1' and 'part 2' RNA was harvested with Trizol (Invitrogen) from control and Fir1(RNAi) tail pieces $48 \mathrm{~h}$ post-amputation. Two biological replicates were used. RNA was amplified and labeled with Cy3-CTP using a low RNA input fluorescent linear amplification kit (Agilent Technologies). Custom oligonucleotide expression arrays (Agilent) were hybridized, scanned and analyzed as previously described (Zeng et al., 2013). To find the downstream genes of Fir1, genes were considered if they met a corrected $P$-value threshold of 0.05 and were downregulated in 'part 1' and showed invariable in 'part 2' in duplicate samples. Hierarchical clustering and heat map generation were performed using $\mathrm{R}$.

\section{Phylogenetic analysis}

Protein sequence for SMED-FIR1 and SMED-DIS3L2 was aligned with its homologous proteins in other organisms using ClustalW with the default setting (Thompson et al., 1994). The result of ClustalW was imported to MEGA 4.0, in which neighbor-joining tree was generated using default settings and 1,000 bootstrap replicates.

\section{TUNEL}

Animals were fixed and stained for TUNEL using a method described elsewhere (Pellettieri et al., 2010) with modifications: animals were bleached in formamide-bleaching solution (5\% non-deionized formamide, $0.5 \times \mathrm{SSC}$, and $1.2 \% \mathrm{H}_{2} \mathrm{O}_{2}$ ) (King and Newmark, 2013) for $4 \mathrm{~h}$ under bright light, after TdT reaction animals were washed $2 \times$ $30 \mathrm{~min}$ at $65^{\circ} \mathrm{C}$ in $1 \mathrm{mmol} / \mathrm{L}$ EDTA, and the TUNEL signal was developed using FITC-tyramide solution (FITC-tyramide 1:1,000 and $0.006 \% \mathrm{H}_{2} \mathrm{O}_{2}$ in PBS containing $0.01 \%$ Tween-20) for $20 \mathrm{~min}$.

Image acquisition, processing and quantification

Live animals and whole-mount in situ hybridization samples were photographed using a microscope (SteREO Discovery.V20; Carl Zeiss) equipped with a Plan Apochromat 1.0x objective and a digital microscope camera (AxioCam HRc; Carl Zeiss) automated by AxioVision Rel.4.8 software (Carl Zeiss). Confocal images were 
captured on a Leica SP5 confocal microscope with a $20 \times$, 40x, or $63 \times$ objective. All the quantifications were using the Measurement program of Volocity (Perkin Elmer) and normalized by the quantified animal area. For $\mathrm{H} 3 \mathrm{P}$ quantifications, all the mitotic events were determined by counting nuclei labeled with the anti-H3P antibody. For quantification of notum ${ }^{+}, w n t^{+}{ }^{+}$or $f s t^{+}$cells, all the probe signals surrounding the nucleus in the vicinity of the wounds were calculated. For cells under apoptosis quantifications, we obtained all the TUNEL signal using confocal microscope (about fifty $1 \mu \mathrm{m}$ stacks), then we used Volocity software (PerkinElmer) to build 3D image for these stacks and quantify $\mathrm{TUNEL}^{+}$nuclei in our region of interest (ROI), and finally the number of TUNEL ${ }^{+}$nuclei was normalized by the area of the upper surface of ROI.

\section{Statistical analysis}

Results are presented as means \pm SEM, and statistical analyses were performed in GraphPad Prism using the Student's $t$ test for two groups. $P<0.05$ was considered significant.

\section{ACKNOWLEDGEMENTS}

We thank P. Newmark, P. Reddien, and N. Oviedo for kindly providing worms. We thank S. Lapan, D. Wenemoser, and K. Kravarik for FISH advice, J. Wolfswinkel for FACS assistance. We thank X. Qiu and J. Chen for critically reading the manuscript. We thank all members of Jing lab for comments and discussion. We thank the staff in the core facility (Institute of Health Sciences) for technical assistance. This work was supported in part by the National Key Research and Development Program of China (2017YFA0103700), the Strategic Priority Research Program of the Chinese Academy of Sciences (XDA16020903), and the National Natural Science Foundation of China (91739301, 91339205, and 31229002).

\section{ABBREVIATIONS}

ASCs, adult stem cells; dFISH, double fluorescent in situ hybridization; FACS, fluorescence-activated cell sorting; H3P, phosphorylated histone $\mathrm{H} 3$ at serine 10; RNAi, RNA interference; TUNEL, terminal deoxynucleotidyl transferase dUTP nick end labeling; WISH, wholemount in situ hybridization.

\section{COMPLIANCE WITH ETHICS GUIDELINES}

Xiao-Shuai Han, Chen Wang, Fang-hao Guo, Shuang Huang, YongWen Qin, Xian-Xian Zhao and Qing Jing declare that they have no conflict of interest. All institutional and national guidelines for the care and use of laboratory animals were followed.

\section{OPEN ACCESS}

This article is distributed under the terms of the Creative Commons Attribution 4.0 International License (http://creativecommons.org/ licenses/by/4.0/), which permits unrestricted use, distribution, and reproduction in any medium, provided you give appropriate credit to the original author(s) and the source, provide a link to the Creative Commons license, and indicate if changes were made.

\section{REFERENCES}

Almuedo-Castillo M, Crespo X, Seebeck F, Bartscherer K, Salò E, Adell T, Aboobaker AA (2014) JNK Controls the onset of mitosis in planarian stem cells and triggers apoptotic cell death required for regeneration and remodeling. PLoS Genetics 10(6):e1004400

Astuti D, Morris MR, Cooper WN, Staals RH, Wake NC, Fews GA, Gill H, Gentle D, Shuib S, Ricketts CJ et al (2012) Germline mutations in DIS3L2 cause the Perlman syndrome of overgrowth and Wilms tumor susceptibility. Nat Genet 44:277-284

Bardeen C, Baetjer F (1904) The inhibitive action of the Roentgen rays onregeneration in planarians. J Exp Zool 1:191-195

Beachy PA, Karhadkar SS, Berman DM (2004) Tissue repair and stem cell renewal in carcinogenesis. Nature 432:324-331

Best JB, Hand S, Rosenvold R (1968) Mitosis in normal and regenerating planarians. J Exp Zool 168(2):157-167

Blassberg RA, Felix DA, Tejada-Romero B, Aboobaker AA (2013) $\mathrm{PBX} /$ extradenticle is required to re-establish axial structures and polarity during planarian regeneration. Development 140(4):730739

Bonuccelli L, Rossi L, Lena A, Scarcelli V, Rainaldi G, Evangelista M, lacopetti P, Gremigni V, Salvetti A (2010) An RbAp48-like gene regulates adult stem cells in planarians. J Cell Sci 123 (5):690-698

Böser A, Drexler HC, Reuter H, Schmitz H, Wu G, Schöler HR, Gentile L, Bartscherer K (2013) SILAC proteomics of planarians identifies Ncoa5 as a conserved component of pluripotent stem cells. Cell Rep 5(4):1142-1155

Carlson ME, Hsu M, Conboy IM (2008) Imbalance between pSmad3 andNotch induces CDK inhibitors in old muscle stem cells. Nature 454:528-532

Chang HM, Triboulet R, Thornton JE, Gregory RI (2013) A role for the Perlman syndrome exonuclease Dis312 in the Lin28-let-7 pathway. Nature 497:244-248

Chen CCG, Wang IE, Reddien PW (2013) pbx is required for pole and eye regeneration in planarians. Development 140(4):719729

Clarke DL, Johansson CB, Wilbertz J, Veress B, Nilsson E, Karlstrom H, Lendahl U, Frisen J (2000) Generalized potential of adult neural stem cells. Science 288:1660-1663

Cowles MW, Hubert A, Zayas RM (2012) A Lissencephaly-1 homologue is essential for mitotic progression in the planarian Schmidtea mediterranea. Dev Dyn 241:901-910

Dubois F (1949) Contribution á I 'ètude de la migration des cellules de règènèration chez les Planaires dulcicoles. Bull Biol Fr Belg 83:213-283

Fuchs E, Segre JA (2000) Stem cells: a new lease on life. Cell 100:143-155

Fuchs Y, Steller H (2015) Live to die another way: modes of programmed cell death and the signals emanating from dying cells. Nature Reviews Molecular Cell Biology 16(6):329-344

Gavino MA, Wenemoser D, Wang IE, Reddien PW (2013) Tissue absence initiates regeneration through follistatin-mediated inhibition of activin signaling. Elife 2:e00247

Gentile L, Cebria F, Bartscherer K (2011) The planarian flatworm: an in vivo model for stem cell biology and nervous system regeneration. Dis Models Mech 4:12-19 
Gonzalez-Estevez C, Felix DA, Smith MD, Paps J, Morley SJ, James V, Sharp TV, Aboobaker AA (2012) SMG-1 and mTORC1 act antagonistically to regulate response to injury and growth in planarians. Plos Genetics 8:e1002619

Govindasamy N, Murthy S, Ghanekar Y (2014) Slow-cycling stem cells in hydra contribute to head regeneration. Biol Open 3:12361244

Guo T, Peters AH, Newmark PA (2006) A bruno-like gene is required for stem cell maintenance in planarians. Dev Cell 11(2):159-169

Hayashi T, Asami M, Higuchi S, Shibata N, Agata K (2006) Isolation of planarian X-ray-sensitive stem cells by fluorescence-activated cell sorting. Dev Growth Differ 48:371-380

Hollenbach JP, Resch AM, Palakodeti D, Graveley BR, Heinen CD, Martin G (2011) Loss of DNA mismatch repair imparts a selective advantage in planarian adult stem cells. PLoS ONE 6(7):e21808

Hopman AH, Ramaekers FC, Speel EJ (1998) Rapid synthesis of biotin-, digoxigenin-, trinitrophenyl-, and fluorochrome-labeled tyramides and their application for In situ hybridization using CARD amplification. J Histochem Cytochem 46:771-777

Kao D, Felix D, Aboobaker A (2013) The planarian regeneration transcriptome reveals a shared but temporally shifted regulatory program between opposing head and tail scenarios. BMC Genomics 14:797

King RS, Newmark PA (2013) In situ hybridization protocol for enhanced detection of gene expression in the planarian Schmidtea mediterranea. BMC Dev Biol 13:8

Labbe RM, Irimia M, Currie KW, Lin A, Zhu SJ, Brown DD, Ross EJ, Voisin V, Bader GD, Blencowe BJ et al (2012) A comparative transcriptomic analysis reveals conserved features of stem cell pluripotency in planarians and mammals. Stem Cells 30:17341745

Lapan SW, Reddien PW (2011) dlx and sp6-9 Control optic cup regeneration in a prototypic eye. PLoS Genet 7:e1002226

Li YQ, Zeng A, Han XS, Wang C, Li G, Zhang ZC, Wang JY, Qin YW, Jing $Q$ (2011) Argonaute-2 regulates the proliferation of adult stem cells in planarian. Cell Res 21:1750-1754

Morgan T (1898) Experimental studies of the regeneration of Planaria maculata. Arch Entw Mech Org 7:364-397

Morgan TH (1901) Regeneration. Macmillan, New York, p 316

Newmark PA, Sanchez Alvarado A (2000) Bromodeoxyuridine specifically labels the regenerative stem cells of planarians. Dev Biol 220:142-153

Onal P, Grun D, Adamidi C, Rybak A, Solana J, Mastrobuoni G, Wang Y, Rahn HP, Chen W, Kempa S et al (2012) Gene expression of pluripotency determinants is conserved between mammalian and planarian stem cells. EMBO J 31:2755-2769

Oviedo NJ, Levin M (2007) smedinx-11 is a planarian stem cell gap junction gene required for regeneration and homeostasis. Development 134(17):3121-3131

Palakodeti D, Smielewska M, Lu YC, Yeo GW, Graveley BR (2008) The PIWI proteins SMEDWI-2 and SMEDWI-3 are required for stem cell function and piRNA expression in planarians. RNA 14 (6):1174-1186

Passamaneck YJ, Martindale MQ (2012) Cell proliferation is necessary for the regeneration of oral structures in the anthozoan cnidarian Nematostella vectensis. BMC Dev Biol 12:34
Pearson BJ, Sanchez Alvarado A (2010) A planarian p53 homolog regulates proliferation and self-renewal in adult stem cell lineages. Development 137:213-221

Pearson BJ, Eisenhoffer GT, Gurley KA, Rink JC, Miller DE, Sanchez Alvarado A (2009) Formaldehyde-based whole-mount in situ hybridization method for planarians. Dev Dyn 238:443-450

Pellettieri J, Sanchez Alvarado A (2007) Cell turnover and adult tissue homeostasis: from humans to planarians. Annu Rev Genet 41:83-105

Pellettieri J, Fitzgerald P, Watanabe S, Mancuso J, Green DR, Sanchez Alvarado A (2010) Cell death and tissue remodeling in planarian regeneration. Dev Biol 338:76-85

Porrello ER, Mahmoud AI, Simpson E, Hill JA, Richardson JA, Olson EN, Sadek HA (2011) Transient regenerative potential of the neonatal mouse heart. Science 331:1078-1080

Reddien PW, Sanchez Alvarado A (2004) Fundamentals of planarian regeneration. Annu Rev Cell Dev Biol 20:725-757

Reddien PW, Oviedo NJ, Jennings JR, Jenkin JC, Alvarado AS (2005a) SMEDWI-2 is a PIWI-like protein that regulates planarian stem cells. Science 310:1327-1330

Reddien PW, Oviedo NJ, Jennings JR, Jenkin JC, Sanchez Alvarado A (2005b) SMEDWI-2 is a PIWI-like protein that regulates planarian stem cells. Science 310:1327-1330

Rossi L, Salvetti A, Marincola FM, Lena A, Deri P, Mannini L, Batistoni R, Wang E, Gremigni V (2007) Deciphering the molecular machinery of stem cells: a look at the neoblast gene expression profile. Genome Biol 8:R62

Rouhana L, Shibata N, Nishimura O, Agata K (2010) Different requirements for conserved post-transcriptional regulators in planarian regeneration and stem cell maintenance. Dev Biol 341(2):429-443

Rouhana L, Vieira AP, Roberts-Galbraith RH, Newmark PA (2012) PRMT5 and the role of symmetrical dimethylarginine in chromatoid bodies of planarian stem cells. Development 139:1083-1094

Rouhana L, Weiss JA, Forsthoefel DJ, Lee H, King RS, Inoue T, Shibata N, Agata K, Newmark PA (2013) RNA interference by feeding in vitro-synthesized double-stranded RNA to planarians: methodology and dynamics. Dev Dyn 242:718-730

Salvetti A (2005) DjPum, a homologue of Drosophila Pumilio, is essential to planarian stem cell maintenance. Development 132 (8):1863-1874

Sanchez Alvarado A (2000) Regeneration in the metazoans: why does it happen? BioEssays 22:578-590

Sanchez Alvarado A (2003) The freshwater planarian Schmidtea mediterranea: embryogenesis, stem cells and regeneration. Curr Opin Genet Dev 13:438-444

Sanchez Alvarado A, Newmark PA, Robb SM, Juste R (2002) The Schmidtea mediterranea database as a molecular resource for studying platyhelminthes, stem cells and regeneration. Development 129:5659-5665

Scimone ML, Meisel J, Reddien PW (2010) The Mi-2-like SmedCHD4 gene is required for stem cell differentiation in the planarian Schmidtea mediterranea. Development 137:12311241

Scimone ML, Kravarik KM, Lapan SW, Reddien PW (2014) Neoblast specialization in regeneration of the planarian Schmidtea mediterranea. Stem Cell Rep 3:339-352 
Seifert AW, Kiama SG, Seifert MG, Goheen JR, Palmer TM, Maden M (2012) Skin shedding and tissue regeneration in African spiny mice (Acomys). Nature 489:561-565

Shaw RL, Kohlmaier A, Polesello C, Veelken C, Edgar BA, Tapon N (2010) The Hippo pathway regulates intestinal stem cell proliferation during Drosophila adult midgut regeneration. Development 137:4147-4158

Solana J, Kao D, Mihaylova Y, Jaber-Hijazi F, Malla S, Wilson R, Aboobaker A (2012) Defining the molecular profile of planarian pluripotent stem cells using a combinatorial RNAseq, RNA interference and irradiation approach. Genome Biol 13:R19

Thompson JD, Higgins DG, Gibson TJ (1994) CLUSTAL W: improving the sensitivity of progressive multiple sequence alignment through sequence weighting, position-specific gap penalties and weight matrix choice. Nucleic Acids Res 22:4673-4680

Ustianenko D, Hrossova D, Potesil D, Chalupnikova K, Hrazdilova K, Pachernik J, Cetkovska K, Uldrijan S, Zdrahal Z, Vanacova S (2013) Mammalian DIS3L2 exoribonuclease targets the uridylated precursors of let-7 miRNAs. RNA 19:1632-1638

van Wolfswinkel JC, Wagner DE, Reddien PW (2014) Single-cell analysis reveals functionally distinct classes within the planarian stem cell compartment. Cell Stem Cell 15:326-339

Wagner DE, Wang IE, Reddien PW (2011) Clonogenic neoblasts are pluripotent adult stem cells that underlie planarian regeneration. Science 332:811-816

Wagner DE, Ho JJ, Reddien PW (2012) Genetic regulators of a pluripotent adult stem cell system in planarians identified by RNAi and clonal analysis. Cell Stem Cell 10:299-311

Wang YZ, Yamagami T, Gan Q, Wang Y, Zhao T, Hamad S, Lott P, Schnittke N, Schwob JE, Zhou CJ (2011) Canonical Wnt signaling promotes the proliferation and neurogenesis of peripheral olfactory stem cells during postnatal development and adult regeneration. J Cell Sci 124:1553-1563

Wang C, Han XS, Li FF, Huang S, Qin YW, Zhao XX, Jing Q (2016) Forkhead containing transcription factor Albino controls tetrapyrrole-based body pigmentation in planarian. Cell Discov. https://doi.org/10.1038/celldisc.2016.29

Wenemoser D, Reddien PW (2010) Planarian regeneration involves distinct stem cell responses to wounds and tissue absence. Dev Biol 344:979-991

Wenemoser D, Lapan SW, Wilkinson AW, Bell GW, Reddien PW (2012) A molecular wound response program associated with regeneration initiation in planarians. Genes Dev 26:988-1002

Wurtzel O, Cote LE, Poirier A, Satija R, Regev A, Reddien PW (2015) A Generic and Cell-Type-Specific Wound Response Precedes Regeneration in Planarians. Dev Cell 35:632-645

Zayas RM, Hernández A, Habermann B, Wang Y, Stary JM, Newmark PA (2005) The planarian Schmidtea mediterranea as a model for epigenetic germ cell specification: Analysis of ESTs from the hermaphroditic strain. Proc Nat Acad Sci 102 (51):18491-18496

Zeng A, Li YQ, Wang C, Han XS, Li G, Wang JY, Li DS, Qin YW, Shi $Y$, Brewer $\mathrm{G}$ et al (2013) Heterochromatin protein 1 promotes selfrenewal and triggers regenerative proliferation in adult stem cells. J Cell Biol 201:409-425

Zhu SJ, Pearson BJ (2013) The Retinoblastoma pathway regulates stem cell proliferation in freshwater planarians. Dev Biol 373 (2):442-452

Zhu SJ, Hallows SE, Currie KW, Xu C, Pearson BJ (2015) A mex3 homolog is required for differentiation during planarian stem cell lineage development. eLife 4 